\title{
Recent Progress of Organic Photovoltaics with Efficiency over $17 \%$
}

\author{
Xuelin Wang ${ }^{1}{ }^{\mathbb{D}}$, Qianqian Sun ${ }^{2}$, Jinhua Gao ${ }^{1}$, Jian Wang ${ }^{3}$, Chunyu $\mathrm{Xu}^{1}{ }^{1}$, Xiaoling Ma ${ }^{1, *}$ and Fujun Zhang ${ }^{1, *}$ \\ 1 School of Science, Beijing Jiaotong University, Beijing 100044, China; 19121595@bjtu.edu.cn (X.W.); \\ 18118027@bjtu.edu.cn (J.G.); 18121672@bjtu.edu.cn (C.X.) \\ 2 School of Physics and Electronics, Shandong Normal University, Jinan 250014, China; \\ qianqiansun@sdnu.edu.cn \\ 3 College of Physics and Electronic Engineering, Taishan University, Taian 271021, China; wangjian@tsu.edu.cn \\ * Correspondence: maxl@bjtu.edu.cn (X.M.); fjzhang@bjtu.edu.cn (F.Z.)
}

Citation: Wang, X.; Sun, Q.; Gao, J.;

Wang, J.; Xu, C.; Ma, X.; Zhang, F.

Recent Progress of Organic

Photovoltaics with Efficiency over

17\%. Energies 2021, 14, 4200.

https://doi.org/10.3390/en14144200

Academic Editor: Marian Tzolov

Received: 31 May 2021

Accepted: 8 July 2021

Published: 12 July 2021

Publisher's Note: MDPI stays neutral with regard to jurisdictional claims in published maps and institutional affiliations.

Copyright: (c) 2021 by the authors. Licensee MDPI, Basel, Switzerland. This article is an open access article distributed under the terms and conditions of the Creative Commons Attribution (CC BY) license (https:// creativecommons.org/licenses/by/ $4.0 /)$.

\begin{abstract}
The power conversion efficiency (PCE) of organic photovoltaics (OPVs) has exceeded 18\% with narrow bandgap, non-fullerene materials $\mathrm{Y} 6$ or its derivatives when used as an electron acceptor. The PCE improvement of OPVs is due to strong photon harvesting in near-infrared light range and low energy loss. Meanwhile, ternary strategy is commonly recognized as a convenient and efficient means to improve the PCE of OPVs. In this review article, typical donor and acceptor materials in prepared efficient OPVs are summarized. From the device engineering perspective, the typical research work on ternary strategy and tandem structure is introduced for understanding the device design and materials selection for preparing efficient OPVs.
\end{abstract}

Keywords: power conversion efficiency; organic photovoltaics; non-fullerene materials; ternary strategy; tandem structure

\section{Introduction}

Environmental pollution and energy shortage have become the main issues restricting society development due to consumption of fossil fuels and excessive exploitation. In recent decades, increasingly more attention has been paid to environment friendly green energy, especially for solar energy, nuclear energy and wind energy [1,2]. Organic photovoltaics (OPVs) are developed to achieve the conversion from solar energy to electrical energy. Compared with inorganic photovoltaics, OPVs show unique advantages with blend donor and acceptor materials as solution-processed active layers. Solution-processed materials were synthesized in the form of colloidal semiconductor inks, as shown in Figure 1. Various methods could be used to form a solid film, such as spray coating, spin coating, inkjet printing, doctor blading or roll-to-roll printing [3]. Organic materials have some advantages, such as low-cost, large-area process ability, high absorption coefficients, tunable optical bandgap and energy levels [4,5]. After years of exploration, the device structure of OPVs has evolved from Schottky type to planar heterojunction type, and then to bulk heterojunction (BHJ) type. Currently, BHJ refers to the active layers formed by blending donor and acceptor materials. The donor and acceptor materials are interlaced with each other to form a bicontinuous interpenetrating network nanostructure [6,7]. Sufficient donor/acceptor interface is conducive to exciton dissociation, which strongly determines the performance of OPVs. Some efficient strategies were adopted to optimize phase separation of the active layer, such as solvent additives, thermal annealing treatment, solvent vapor annealing treatment and up-side-down post annealing treatments [8-11]. The active layer optimization method is commonly decided by the molecular structure of donor and acceptor materials. A dozen years ago, fullerene acceptor materials were used as the main acceptor materials of OPVs due to their good electron transport characteristics. Representative chemical structures of fullerene acceptors are shown in Figure 2. The blend of P3HT:PC 61 BM was first 
used as the active layer of OPVs, achieving a PCE of 2.8\% [12]. However, the absorption of fullerene derivatives in the visible light region is relatively weak, and the tunability of the energy levels is limited. It is difficult to realize the breakthrough on the PCE of OPVs based on fullerene derivatives [13]. In contrast, non-fullerene acceptor (NFAs) materials possess readily adjustable energy levels and excellent characteristics on strong light absorption in the near-infrared region, which exhibit great potential in constructing highly efficient OPVs, especially for semitransparent OPVs [14,15]. In 2015, Zhan et al. developed ITIC based on a fused aromatic ring, and non-fullerene PSCs with medium bandgap conjugated polymer as the donor and ITIC as the acceptor had PCEs of 9-11\% [16-18]. In 2019, Zou et al. designed a narrow bandgap NFA material $Y 6$, leading to great improvement on PCE of binary OPVs [19]. Hereafter, a series of $Y 6$ derivatives with narrow bandgap have been successfully designed and synthesized [20,21]. In 2021, a novel non-Y6 acceptor material named M3 was developed by Zheng et al. [22]. A 16.66\% PCE is achieved in PM6:M3 based OPVs, which is comparable with Y6-series acceptor-based OPVs. Here, we summarize in Table 1 the typical works on OPVs with PCE over 17\%, which exhibits great potential for the commercialization of OPVs as a green energy source.

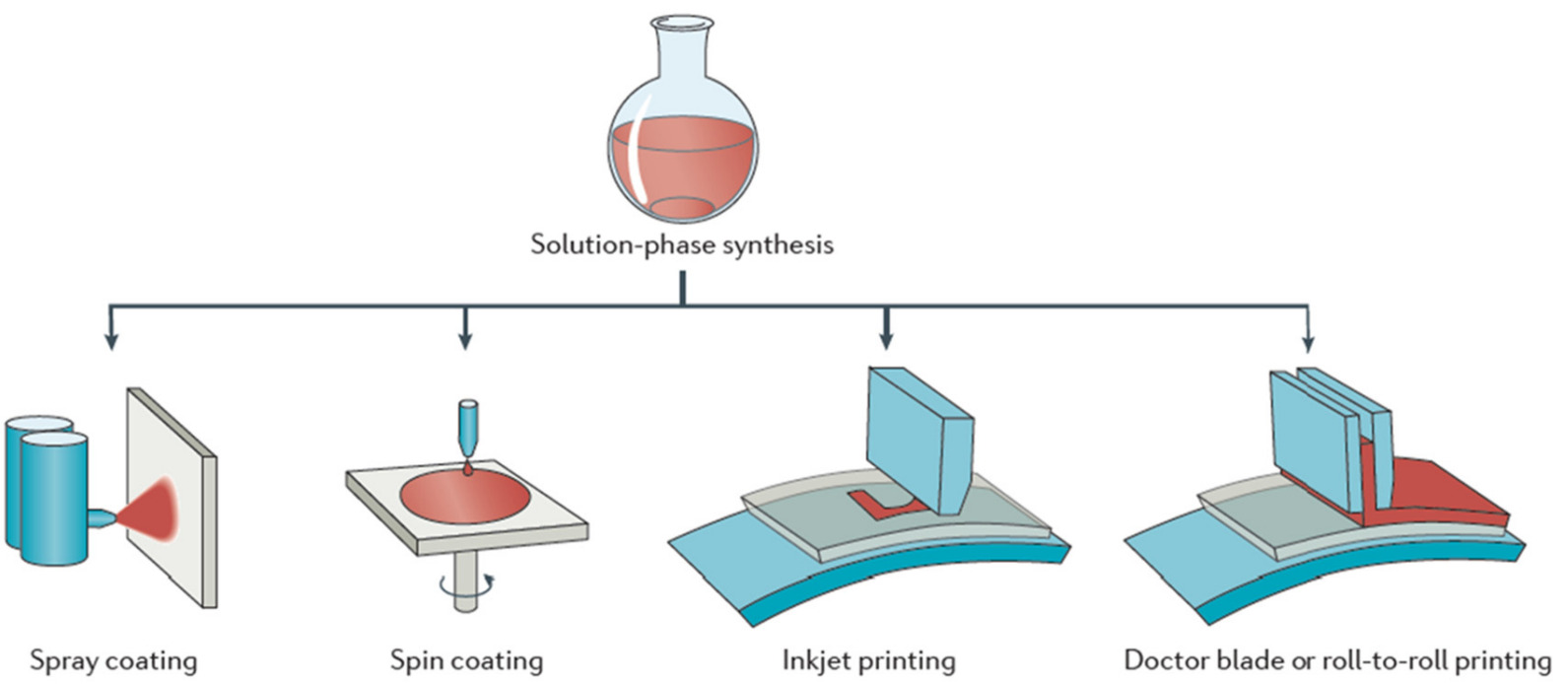

Figure 1. Different film preparation methods for solutions in the form of colloidal semiconductor inks. Reproduced from [3]. Reprinted with permission from ref. [3]. Copyright 2017 Nature Reviews Materials.
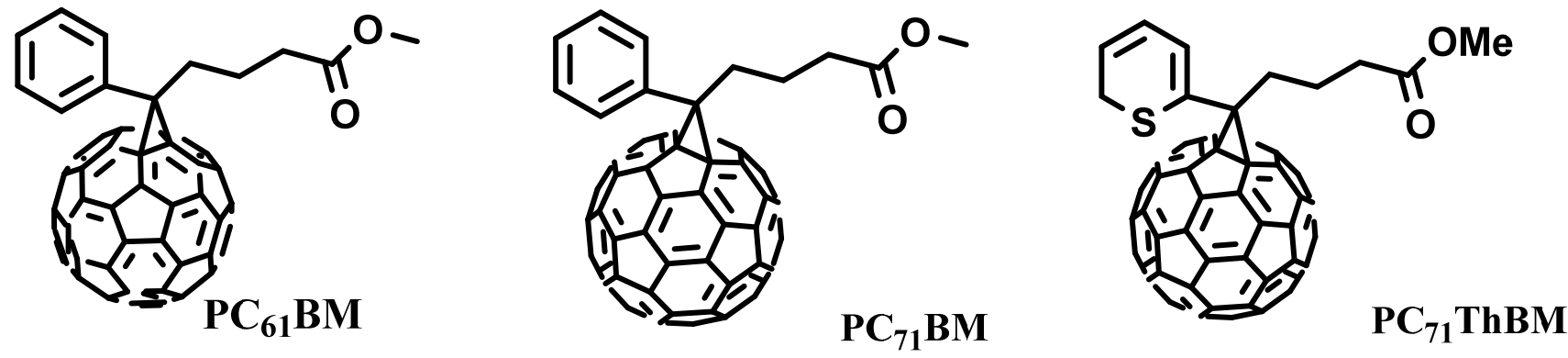

Figure 2. Representative chemical structures of fullerene derivatives.

In this review, we first introduce some $\mathrm{BHJ}$ materials including high-performance acceptors and donors. Next, we study the multicomponent-based OPVs that are mainly divided into ternary OPVs and quaternary OPVs. Then, we study OPVs and integrated perovskite/organic solar cells (IPOSCs) in tandem OPVs. Finally, the application of the recent anode interface materials and cathode interface materials in the high efficiency organic solar cells is studied. 
Table 1. The recent progress of OPVs with efficiency over than $17 \%$.

\begin{tabular}{|c|c|c|c|c|c|c|c|c|}
\hline Active Layer & $\begin{array}{c}\text { Anode } \\
\text { Modification } \\
\text { Layer }\end{array}$ & $\begin{array}{l}\text { Cathode } \\
\text { Modification } \\
\text { Layer }\end{array}$ & $\begin{array}{c}J_{S C} \\
\left(\mathrm{~mA} \mathrm{~cm}^{-2}\right)\end{array}$ & $\begin{array}{c}V_{\mathrm{OC}} \\
(\mathrm{V})\end{array}$ & $\begin{array}{l}\text { FF } \\
(\%)\end{array}$ & $\begin{array}{c}\text { PCE } \\
(\%)\end{array}$ & Years & Ref. \\
\hline PM6:BTP-4Cl-12 & PP & PDINO & 25.60 & 0.858 & 77.60 & 17.00 & 2019 & [23] \\
\hline PM7:Y6 & PP & PNDIT-F3N & 25.61 & 0.882 & 73.30 & 17.04 & 2020 & [24] \\
\hline PM6:BTP-2F-ThCl & PP & PNDIT-F3N & 25.38 & 0.869 & 77.40 & 17.06 & 2020 & [20] \\
\hline PM6:Y6 & PP & PDINN & 25.89 & 0.847 & 78.59 & 17.23 & 2020 & [25] \\
\hline PM6-Ir1:Y6 & $\mathrm{PP}$ & PNDIT-F3N-Br & 26.12 & 0.845 & 78.41 & 17.24 & 2020 & [26] \\
\hline PM1:Y6 & PP & PFN-Br & 25.90 & 0.870 & 78.00 & 17.60 & 2020 & [27] \\
\hline PBQ6:Y6 & PP & PDINN & 26.58 & 0.851 & 77.91 & 17.62 & 2021 & [28] \\
\hline D18:Y6Se & $\mathrm{PP}$ & PNDIT-F3N-Br & 27.98 & 0.839 & 75.30 & 17.70 & 2020 & [29] \\
\hline PM6:BTP-eC9 & PP & PFN-Br & 26.20 & 0.841 & 78.30 & 17.80 & 2020 & [21] \\
\hline D18:Y6 & $\mathrm{PP}$ & PDIN & 27.70 & 0.859 & 76.60 & 18.22 & 2020 & [30] \\
\hline PM6:L8-BO & $\mathrm{PP}$ & PNDIT-F3N-Br & 25.72 & 0.870 & 81.50 & 18.32 & 2021 & [31] \\
\hline D18:N3 & $\mathrm{PP}$ & PDIN & 27.44 & 0.862 & 78.50 & 18.56 & 2021 & [32] \\
\hline PBDB-T-2F:Y6:PC ${ }_{71} \mathrm{BM}$ & $\mathrm{WS}_{2}$ & PFN-Br & 26.00 & 0.840 & 78.00 & 17.00 & 2019 & [33] \\
\hline PM6:DRTB-T-C4:Y6 & $\mathrm{PP}$ & PFN-Br & 24.79 & 0.850 & 81.30 & 17.13 & 2020 & [34] \\
\hline PM6:Y6:PC 71 BM & $\mathrm{MoO}_{3}$ & $\mathrm{ZnO}$ & 26.30 & 0.840 & 77.00 & 17.10 & 2020 & [35] \\
\hline PM6:Y6:PC ${ }_{71} \mathrm{BM}$ & $\mathrm{MoO}_{3}$ & OSiNDs & 26.02 & 0.850 & 77.54 & 17.15 & 2020 & [36] \\
\hline PM6:PYT:PY2F-T & $\mathrm{PP}$ & PNDIT-F3N & 25.20 & 0.900 & 76.00 & 17.20 & 2021 & [37] \\
\hline PM6:Y6:MF1 & PP & PDIN & 25.68 & 0.853 & 78.61 & 17.22 & 2020 & [38] \\
\hline PM6:BTP-4F-12:MeIC & $\mathrm{PP}$ & PDIN & 25.40 & 0.863 & 79.20 & 17.40 & 2020 & [39] \\
\hline PM6:Y6:ITCPTC & $\mathrm{PP}$ & PNDIT-F3N & 25.67 & 0.861 & 78.80 & 17.42 & 2020 & [40] \\
\hline PM6:Y6:BTP-S2 & $\mathrm{PP}$ & PFN-Br & 26.20 & 0.880 & 75.80 & 17.43 & 2020 & [41] \\
\hline PM6:Y6:C8-DTC & $\mathrm{PP}$ & PDINO & 26.50 & 0.873 & 75.61 & 17.52 & 2020 & [42] \\
\hline PM6:S3:Y6 & $\mathrm{PP}$ & PDIN & 25.86 & 0.856 & 79.19 & 17.53 & 2020 & [43] \\
\hline PM6:BTP-4F-12:Y6-1O & PP & PDIN & 26.13 & 0.860 & 78.26 & 17.59 & 2020 & [44] \\
\hline PM6:Y6-1O:PC 71 BM & PP & PNDIT-F3N & 24.90 & 0.900 & 78.50 & 17.60 & 2020 & [45] \\
\hline PM6:BTP-4F-12:IT-M & $\mathrm{PP}$ & PDIN & 25.95 & 0.875 & 78.02 & 17.71 & 2021 & [46] \\
\hline D18-Cl:Y6:Y6-1O & $\mathrm{PP}$ & PDIN & 25.87 & 0.900 & 76.92 & 17.91 & 2021 & [47] \\
\hline PM6:BTP-eC9:PC 71 BM & PP & PFN-Br & 26.93 & 0.856 & 79.40 & 18.30 & 2020 & [48] \\
\hline D18-Cl:N3:PC 61 BM & $\mathrm{PP}$ & PDIN & 28.22 & 0.849 & 78.00 & 18.69 & 2021 & [49] \\
\hline PM6:Y6:IDIC:PC 71 BM & PP & PDINO & 26.19 & 0.866 & 75.29 & 17.07 & 2020 & {$[50]$} \\
\hline PhI-Se:PM6:Y6:PC 71 BM & PP & PDINO & 26.30 & 0.851 & 76.80 & 17.20 & 2020 & [51] \\
\hline PM6:Y6:SR197:PC 71 BM & $\mathrm{MoO}_{3}$ & $\mathrm{ZnO}$ & 27.11 & 0.841 & 76.62 & 17.48 & 2021 & [52] \\
\hline PM6:PTQ10:PC 71 BM:N3 & $\mathrm{PP}$ & PNDIT-F3N & 26.78 & 0.852 & 77.70 & 17.73 & 2020 & {$[53]$} \\
\hline PM6:PM7:Y6:PC 71 BM & PP & PFNDI-Br & 26.55 & 0.859 & 79.23 & 18.07 & 2021 & [54] \\
\hline
\end{tabular}

PP stands for PEDOT:PSS.

\section{Efficient Donor and Acceptor Materials}

In the past ten years, many novel NFAs have been designed, such as those based on a perylenediimide (PDI), naphthalene diimide (NDI) or benzothiadiazole (BT) core. Representative chemical structures of NFAs are shown in Figure 3. The bandgaps, energy levels, planarity and crystallinity characteristics of NFAs can be easily adjusted by chemical modification. Currently, most of the highly efficient OPVs are fabricated with narrow bandgap NFAs as acceptors and wide bandgap polymer as donors [20,21,23-27,29-32]. Zou et al. synthesized a new NFA Y6 exhibiting NIR absorption onset at $931 \mathrm{~nm}$ [19]. The $15.7 \%$ PCE was achieved when blending Y6 with PM6 as active layers, pushing the field of OPVs to a higher level. After that, the scientists focused on how to modify the Y6 molecule and design correspondingly new polymer donors. In 2019, Yao et al. reported a chlorinated NFA named BTP-4Cl by replacing the fluorine atoms on the terminal electron-withdrawing units of $\mathrm{Y} 6$ with chlorine atoms [55]. When blending with polymer donor PM6, BTP-4Cl based OPVs exhibit much higher $V_{O C}$ of $0.867 \mathrm{~V}$ compared with that of the $Y 6$ based OPVs $(0.834 \mathrm{~V})$. According to electroluminescence quantum efficiency (EQE $\left.\mathrm{EL}_{\mathrm{EL}}\right)$ measurement of blend films, the BTP-4Cl based films exhibit a higher EQE $\mathrm{EL}_{\mathrm{EL}}\left(3.47 \times 10^{-4}\right)$ than that of BTP-4F based films $\left(1.40 \times 10^{-4}\right)$, resulting in reduced non-radiative loss of $\sim 24 \mathrm{meV}$. A 
PCE of $16.5 \%$ can be achieved, resulting from concurrently improved $J_{S C}$ of $25.4 \mathrm{~mA} \mathrm{~cm}^{-2}$ and $V_{O C}$ of $0.867 \mathrm{~V}$. It should be noticed that the conjugation area of BTP- $4 \mathrm{Cl}$ increases due to the substitution of fluorine by chlorine atoms, which leads to the poor solubility of BTP-4Cl. When the $0.81 \mathrm{~cm}^{2}$ devices were fabricated by doctor blade coating means, the PCE of large area OPVs dramatically dropped to $10.7 \pm 0.5 \%$, which should be mainly due to poor morphology of blend film caused by limited solubility of BTP-4Cl. To improve the process ability of BTP-4Cl, Yao et al. further prolonged alkyl chains of 2-ethylhexyl on pyrrole rings to 2-hexyldecyl and 2-bultyloctyl [23]. A relatively high PCE of $17 \%$ could be achieved in the PM6:BTP-4Cl-12 based OPVs.

In addition to process ability of materials, the alkyl chains have important influences on intermolecular accumulation and charge transport. Ge et al. modified the alkyl side chains of Y6 and synthesized an NFA BTP-4F-12 [56], as shown in Figure 3. In comparison with $\mathrm{Y} 6$, the longer alkyl side chains of 2-butyloctyl were introduced to BTP-4F-12. Both Y6 and BTP-4F-12 show similar photon harvesting range and energy levels. The chemical property difference between $\mathrm{Y} 6$ and BTP-4F-12 is mainly decided by their molecular arrangement in solid films. The molecular ordering of neat NFA films is studied by using grazing incidence wide-angle X-ray scattering (GIWAXS) measurement. The BTP-4F-12 film has a narrower (100) peak than Y6, and a smaller full width at half-maximum (FWHM, $\Delta q)$. The crystal coherence lengths (CCLs) of the (100) peaks are calculated as 56.5 and $35.3 \AA$ for BTP-4F-12 and BTP-4F-8 films. As the lamellar stacking of the BTP-4F-12 is enhanced, charge transport ability can be improved in the corresponding blend films. All of the active layers were prepared by a spin-coating method with $\mathrm{CF}$ as processing solvent; PBDB-TF:BTP-4F-12 based OPVs exhibit a relatively high PCE of $16.4 \%$ in comparison with 15.3\% of PM6:Y6 based OPVs. More noteworthy is that BTP-4F-12 dissolves better in some low-toxic solvents, such as 1,2,4-TMB, o-xylene and THF. The chemical structures of varied solvents are shown in Figure 4a. The polymer donor PBDB-TF-T1 with greater solubility was selected to replace PM6 as donor. The detailed PCEs of the OPV cells processed by different solvents are shown in Figure $4 \mathrm{~b}$. By employing THF as the processing solvent, a PCE of $16.1 \%$ can be achieved for the PBDB-TF-T1:BTP-4F-12 based OPVs, which is very close to that of OPVs fabricated with halogenated solvents. Furthermore, $1.07 \mathrm{~cm}^{2}$ devices were fabricated by the spin-coating and blade-coating methods (Figure 4c), using THF as the processing solvent. As shown in Figure $4 \mathrm{~d}$, the resulting devices showed similar photovoltaic parameters. Impressively, a high PCE of $14.4 \%$ was still maintained in largearea OPVs with $1.07 \mathrm{~cm}^{2}$ active area prepared by the blade-coating method. The results show that modifying the side chain can achieve the purpose of adjusting the processing ability of materials, and further achieve large-scale production in harmless solvents.

In addition to the central alkyl chains, there are two alkyl chains on the edge of the bithiophene units. In 2020, Yao et al. conducted optimization of alkyl chains on the edge of BTP-4Cl-BO (a Y6 derivative) and studied their applications in OPVs. The BTP-eC9 and BTP-eC7 were successively synthesized by shorting the n-undecyl to n-nonyl and then to n-heptyl [21]. Compared with BTP-BO-4Cl, BTP-eC9 has not only excellent solubility, but also enhanced molecule ordering. The better morphology features of PM6:BTP-eC9 blend films are beneficial to charge transport while inhibiting charge recombination. An outstanding PCE of $17.8 \%$ can be achieved in BTP-eC9 based OPVs, which should be the top levels in the field of OPVs at that time. The BTP-eC7 exhibits relatively low solubility and excessive aggregation in PM6:BTP-eC7 blend films, resulting in a slightly lower PCE of $14.9 \%$. Optimizing the structure of $\mathrm{Y} 6$ derivatives with the same conjugated skeleton is conducive to exploring materials for manufacturing efficient OPVs. 


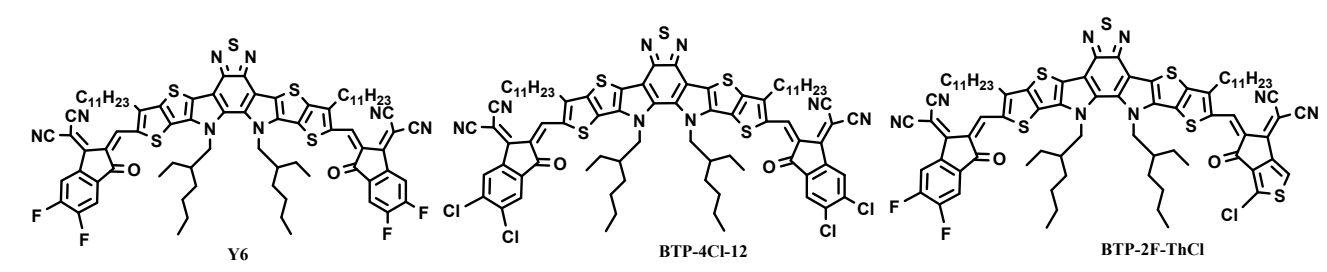
(1) (1)

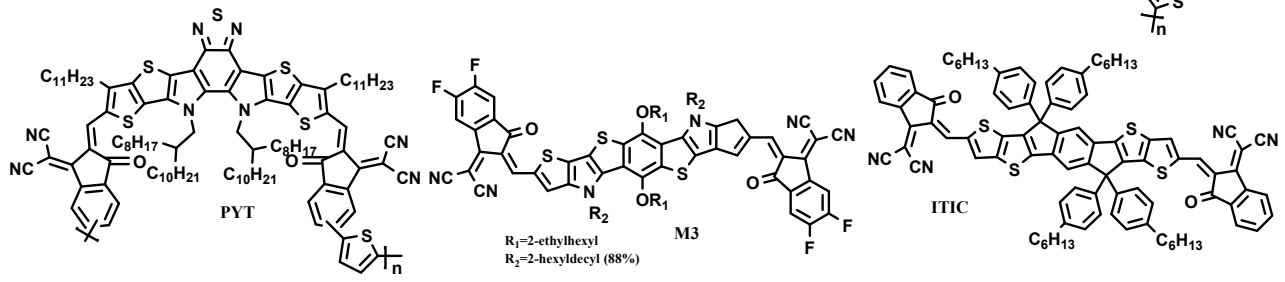
(1) (1) (1) (1T-M (1)

Figure 3. Representative chemical structures of NFAs. 
(a)

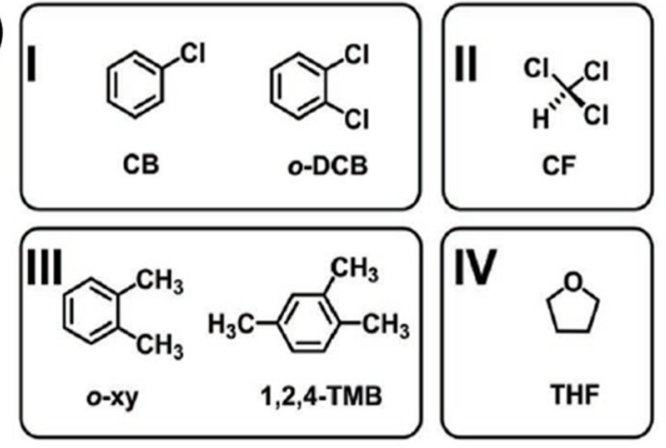

(c)

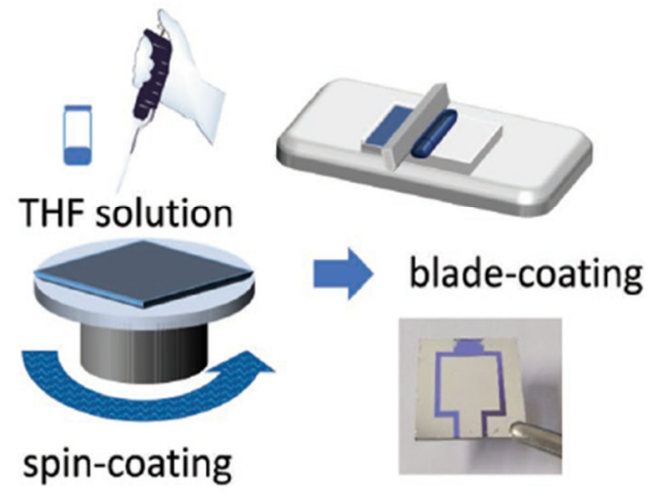

(b)

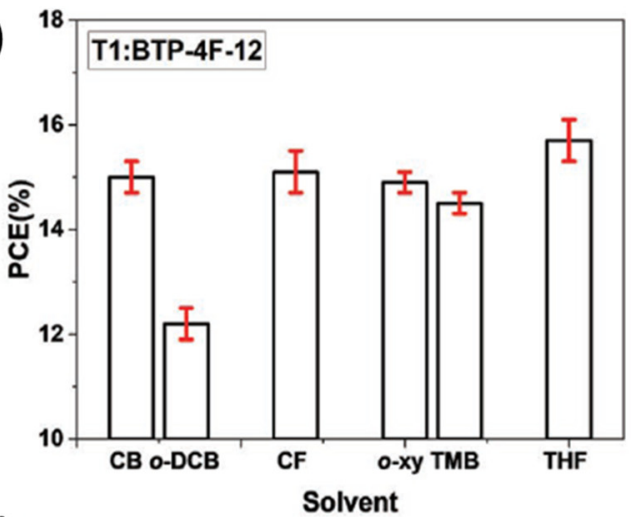

(d)

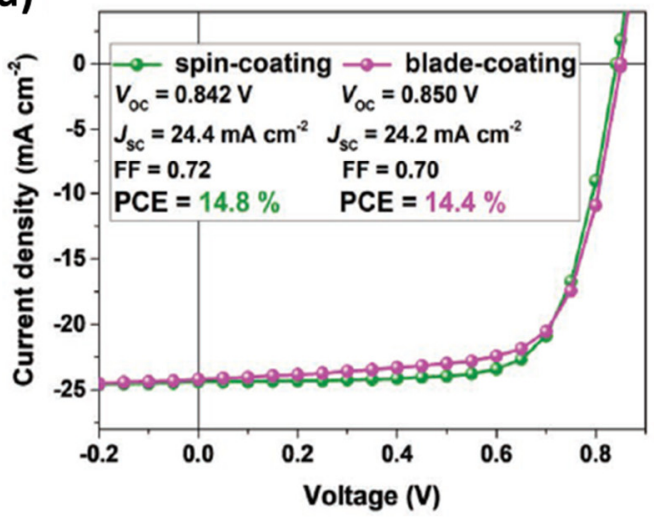

Figure 4. (a) Molecular formulas. (b) PCE histograms. (c) Schematics diagram of the spin-coating and blade-coating processes, and picture of the actual device. (d) The $J-V$ curves of devices at a $1.07 \mathrm{~cm}^{2}$ area. Reproduced from [55].

By improving the Y6 molecule, good chemical properties can be customized. In 2020, $\mathrm{He}$ et al. designed a dissymmetric fused-ring acceptor BTIC-2Cl- $\gamma \mathrm{CF}_{3}$ with chlorine and trifluoromethyl end groups [57]. "When using PBDB-TF as a donor, the toluene-treated binary device achieved a high PCE of $16.31 \%$, which was further increased to $17.12 \%$ when $\mathrm{PC}_{71}$ ThBM was added as the third component $\left(J_{\mathrm{SC}}\right.$ of $25.7 \mathrm{~mA} \mathrm{~cm}^{-2}, V_{\mathrm{OC}}$ of $0.85 \mathrm{~V}$ and FF of 78.10\%)." [57]. Among polymer solar cells treated with non-halogenated solvents, a PCE of more than $17 \%$ is the highest on record. In 2021, Sun et al. synthesized a highly efficient non-fullerene acceptor L8-BO by substituting the beta position of the thiophene unit on a Y6 based dithienothiophen[3,2-b]-pyrrolobenzothiadiazole core with branched alkyl chains [31]. The PM6:L8-BO based ternary OPVs achieved a high PCE of 18.32\% (certified value of $17.9 \%), V_{\mathrm{OC}}$ of $0.874 \mathrm{~V}, \mathrm{JSC}_{\mathrm{SC}}$ of $25.72 \mathrm{~mA} \mathrm{~cm}^{-2}$ and $\mathrm{FF}$ of $81.5 \%$. The emergence of high efficiency $\mathrm{Y} 6$ derivatives provides the possibility to achieve higher efficiency OPVs.

Compared with the emerging NFAs, high-performance donors matching those lowbandgap NFAs are still few. A series of typical donors have been synthesized, such as PBDB-T, PTB7-Th, PM6, PM7 and others. Representative chemical structures of polymer donors are shown in Figure 5. Hou et al. reported a D-A type copolymer PM6 in 2015. The introduction of BDT-F units can effectively lower the highest occupied molecular orbital (HOMO) and the LUMO levels of materials, leading to improved photovoltaic performance. Unfortunately, synthesis cost of the OPV materials containing fluorine is very high $[58,59]$. In 2018, Hou et al. further modified PM6, chlorinated the side groups of thiophene and synthesized a new copolymer PM7 with a similar chemical structure [60]. Compared with fluorinated polymers, the chlorinated polymers have obviously lower synthesis cost and similar optoelectronic properties. The relatively low HOMO level of PM7 is helpful for improving $V_{\mathrm{OC}}$ of the resulting OPVs. The two polymers (PM6 and PM7) were blended with IT-4F to fabricate OPVs under the same preparation conditions. The PM6:IT-4F based OPVs exhibited a PCE of $13.2 \%$, with $J_{\mathrm{SC}} 20.81 \mathrm{~mA} \mathrm{~cm}^{-2}, V_{\mathrm{OC}} 0.84 \mathrm{~V}$ and FF of $76 \%$. The PM7:IT-4F based OPVs showed a higher PCE of $14.4 \%$, with $J_{\mathrm{SC}}$ of $21.80 \mathrm{~mA} \mathrm{~cm}^{-2}, V_{\mathrm{OC}}$ of 
$0.86 \mathrm{~V}$ and FF of $77 \%$. The result demonstrates that introducing chlorine into appropriate substituent positions is an effective strategy for preparing an efficient polymer donor. In 2019, Huang et al. synthesized a new D-A copolymer (P2F-EHp) in which deep HOMO level is achieved by a strong electron-withdrawing difluorophenyl group [61]. A PCE of $16.02 \%$ can be achieved in devices based on P2F-EHp:BTPTT-4F, benefiting from $J_{S C}$ of $26.68 \mathrm{~mA} \mathrm{~cm}^{-2}, V_{O C}$ of $0.81 \mathrm{~V}$ and FF of $74.11 \%$.
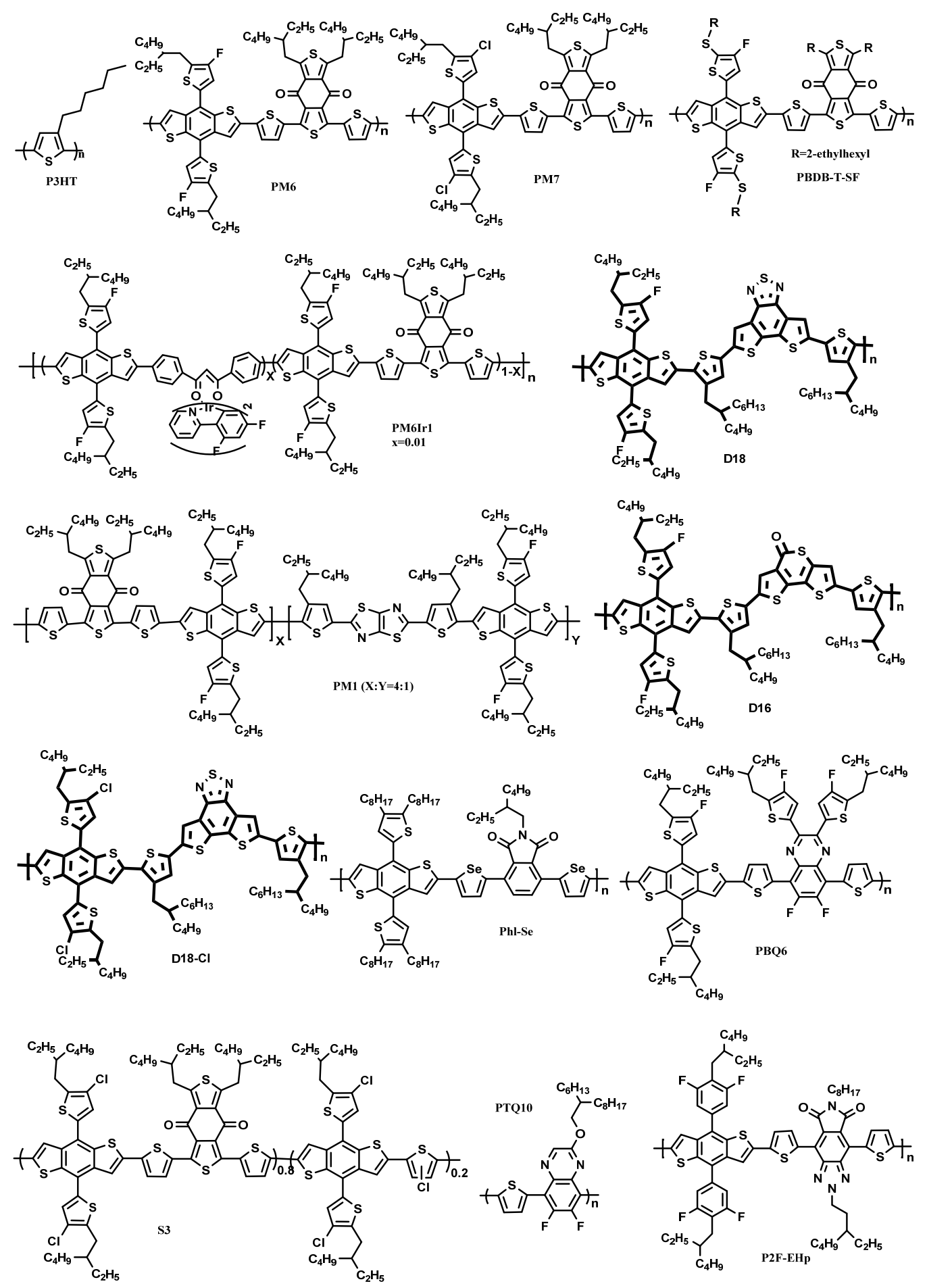

Figure 5. Representative chemical structures of polymer donors.

There is a great mission for the field to develop more high-performance donors that are well matched with NFAs. In 2019, Ding et al. synthesized D16 based on a fused-ring 
thiolactone unit, 5H-dithieno[3,2-b:20,30-d]thiopyran-5-one (DTTP) [62]. These units have strong electron-withdrawing capability and extended molecular planes, giving copolymers deep HOMO levels, high hole mobility and enhanced $\pi-\pi$ stacking. A PCE of $16.72 \%$ can be achieved in D16:Y6 based OPVs. In 2020, Ding et al. further modified D16 and synthesized D18 by using a fused-ring acceptor unit, dithieno[ $\left.3^{\prime}, 2^{\prime}: 3,4 ; 2^{\prime \prime}, 3^{\prime \prime}: 5,6\right]$ benzo $[1,2,5]$ thiadiazole (DTBT) [30]. In comparison with DTTP, DTBT has a larger molecular plane, which gives D18 a higher hole mobility of $1.59 \times 10^{-3} \mathrm{~cm}^{2} \mathrm{~V}^{-1} \mathrm{~s}^{-1}$. A high PCE of $18.22 \%$ (certified 17.6\%) can be achieved in D18:Y6 based OPVs, which should be one of the highest PCE of OPVs.

Incorporating suitable units into the polymer backbone has been proven to be an effective means to improve the microstructure of blend films. Based on this concept, aplatinum (II) complexation strategy was developed by Peng et al. in 2019. A widebandgap copolymer PSFTZ was designed and synthesized based on benzodithiophene (BDT) donor unit and polynitrogen heterocyclic s-tetrazine (s-TZ) acceptor block [63]. PSFTZ exhibits a wide bandgap of $1.93 \mathrm{eV}$ and a low-lying HOMO level of $-5.50 \mathrm{eV}$, which matched well with efficient NFA Y6. The small HOMO level offset of $0.15 \mathrm{eV}$ between PSFTZ and Y6 enabled a relatively low $E_{\text {loss }}$ of $0.53 \mathrm{eV}$. Due to the strong aggregation characteristics of PSFTZ, the phase separation of this active layer was relatively large, which was not conducive to the exciton dissociation and increased the probability of charge recombination. The PSFTZ:Y6 based OPVs show a relatively low PCE of 13.03\%, with $J_{S C}$ of $25.10 \mathrm{~mA} \mathrm{~cm}^{-2}$, FF of $64.9 \%$ and $V_{O C}$ of $0.80 \mathrm{~V}$. In order to study the effect of Pt complexation on crystallinity and molecular packing behavior, 2D-GIWAXS measurements were performed on polymer films with different Pt-complexation degrees, as shown in Figure 6. The coherent length $\left(L_{C}\right)$ based on the (100) diffraction peak is gradually reduced from $131 \AA^{-1}$ to $95 \AA^{-1}$ along with the increase of the Pt-complexation degree. The intensity of (200) and (300) diffractions were simultaneously lowered with increasing the Pt-complexation degree. From the GIWAXS measurement, the introduction of platinum(II) complexation strategy can effectively inhibit the aggregation tendency of the polymer. When a certain amount of $\mathrm{Pt}(\mathrm{Ph})_{2}(\mathrm{DMSO})_{2}$ was added, organometallic complexation could occur between the $\mathrm{Pt}(\mathrm{Ph})_{2}(\mathrm{DMSO})_{2}$ and PSFTZ. Due to the steric hindrance of the benzene ring to the platinum complex, the aggregation strength of the polymer is suppressed, and the phase separation and film morphology are improved. The optimal PCE is significantly improved from $13.03 \%$ to $16.35 \%$ by adding $10 \%$ (molar ratio related to the s-TZ block) $\mathrm{Pt}(\mathrm{Ph})_{2}(\mathrm{DMSO})_{2}$, with enhanced $J_{\mathrm{SC}}$ of $26.45 \mathrm{~mA} \mathrm{~cm}^{-2}$ and FF of $76.3 \%$. In 2020, Min et al. further developed highly efficient polymer donor materials based on a similar strategy. Different concentrations of iridium (Ir) complexes (0, 0.5, 1, 2.5 and $5 \mathrm{~mol} \%$; (dfppy) ${ }_{2} \mathrm{IrdbmBr}$ ) were introduced into the polymer conjugated backbone of the commercially available polymer PM6 [26]. A series of OPVs were fabricated with PM6-Irx $(\mathrm{x}=0,0.5,1,2.5$ and 5):Y6 as active layers. The addition of iridium (Ir) complexes into the PM6 can effectively improve BHJ morphology and simultaneously facilitate charge generation, accelerate carrier extraction and hinder carrier recombination. The optimal PCE of $17.24 \%$ can be achieved by adding $1 \mathrm{~mol} \%$ of (dfppy) ${ }_{2}$ IrdbmBr unit, with simultaneously enhanced $V_{O C}, J_{S C}$ and FF of $0.845 \mathrm{~V}, 26.12 \mathrm{~mA} \mathrm{~cm}^{-2}$ and $78.41 \%$, respectively.

In recent years, more PM6 derivatives with excellent performance have been designed and synthesized to achieve higher efficiency OPVs. In 2020, Zhang et al. synthesized a donor polymer (named PM1) by including 20\% weakly electron-withdrawing thiophenethiazolothiazole (TTz) in the PM6 polymer backbone [27]. The PM1:Y6 based OPVs can achieve high PCE of $17.6 \%, J_{\mathrm{SC}}$ of $25.9 \mathrm{~mA} \mathrm{~cm}^{-2}, V_{\mathrm{OC}}$ of $0.87 \mathrm{~V}$ and FF of $78 \%$. Excitingly, PM1 polymer has excellent batch-to-batch reproducibility compared to PM6, which is expected to become the main material of the non-fullerene OPV community. In 2021, Li et al. synthesized a D-A copolymer (PBQ6), which is based on biphenyl-benzodithiophene (BDTT) as the donor (D) unit and difluroquinoxaline (DFQ) with two alkyl-substituted fluorothiophene side chains as the acceptor (A), and thiophene as the $\pi$-bridges [28]. The mixed film of PBQ6:Y6 showed more balanced hole/electron mobility, less charge 
carrier recombination and a more favorable morphology compared with the mixed film of PBQ5:Y6. Therefore, the OPVs based on PBQ6:Y6 achieved a high PCE of 17.62\% (JSC of $26.58 \mathrm{~mA} \mathrm{~cm}^{-2}, V_{\mathrm{OC}}$ of $0.851 \mathrm{~V}$ and FF of $77.91 \%$ ), which is one of the highest PCE of binary OPV with polymer donor and $\mathrm{Y} 6$ acceptor. The emergence of multifarious donors provides the possibility of achieving higher efficiency OPVs.
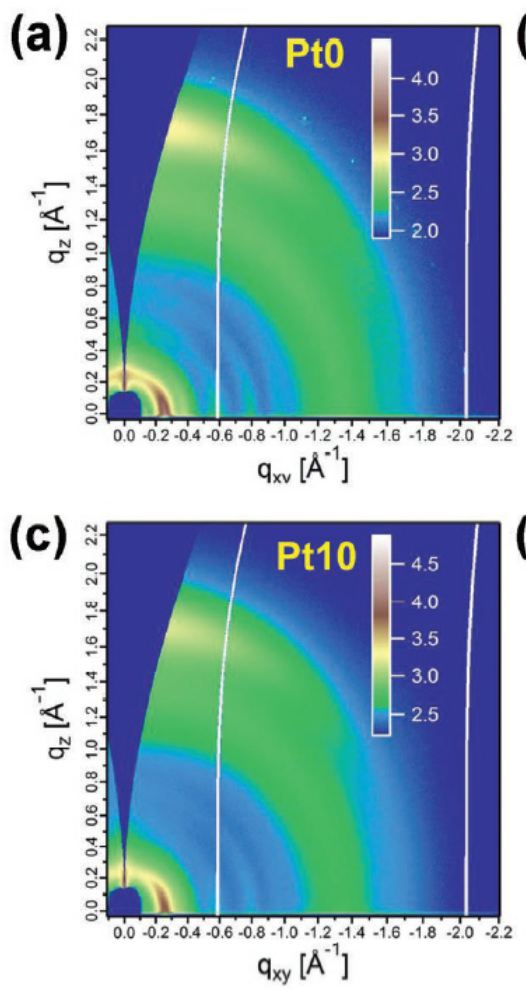
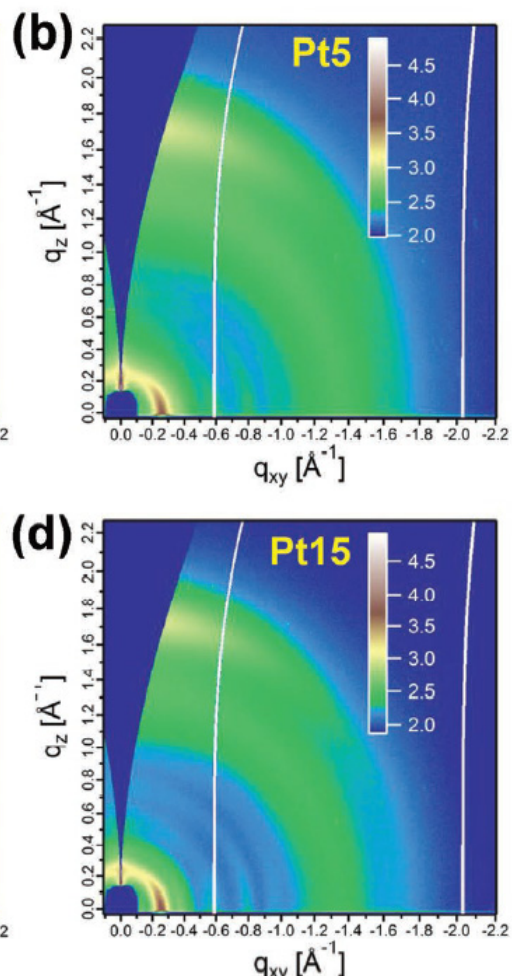

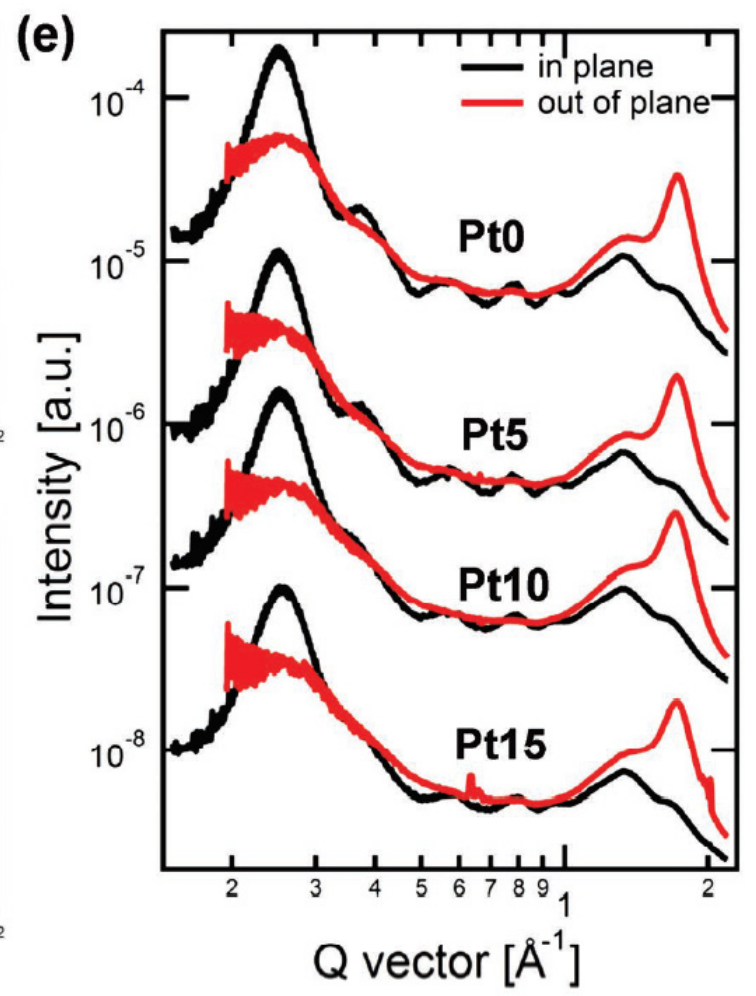

Figure 6. (a-d) The 2D-GIWXAS patterns. (e) IP and OOP line-cut profiles. Reproduced from [63]. Reprinted with permission from ref. [63]. Copyright 2019 Wiley.

\section{Device Architecture}

Single-junction OPVs have made great progress, mostly due to the complementary absorption spectra, matched energy levels and good compatibility of NFA and polymer donors $[64,65]$. It is well recognized that the absorption spectrum of organic materials is relatively narrow, which restricts the photon capture range of the multielement blend film. Enhanced photon capture ability of the active layer is the first step to achieve high efficiency OPVs [66-68]. It is found that if the width of the absorption window is doubled, PCE of OPV may be greatly improved [69]. Obviously, the active layer containing multiple components with complementary absorption spectra not only enhances photon capture, but also maintains a simple manufacturing process [70,71]. In addition, the introduced third or fourth component provides a variety of functions for the improvement of OPV performance, such as enhancing photon capture, optimizing distribution of photogenerated excitons, altering molecular arrangement and optimizing phase separation degree [72-74]. The important photovoltaic parameters of OPVs can be optimized to the maximum simultaneously or individually by incorporating appropriate third or fourth components as a photon harvesting enhancer and morphology regulator. Alternatively, in comparison with single-junction configuration, tandem OPVs can not only expand the photon absorption range and enhance the photon absorption intensity, but also decrease heat loss by stacking multiple subcells with different absorption ranges [75]. In fact, several technological challenges must be accurately controlled to fabricate high performance tandem OPVs, such as active layer thickness of each subcell, transmission and charge carrier collection ability of intermediate cathode, and the complementarities of active layer absorption spectra in each 
subcell. Multicomponents and tandem strategy have been proven to be an efficient method to achieve performance improvement of OPVs. In addition, the development of interface engineering is also crucial to the preparation of high efficiency OPVs. The interface layers between organic active layers and electrodes play a vital role in determining the charge extraction dynamic process, which is closely related to FF of OPVs. PEDOT:PSS and PDIN are commonly employed as a hole transport intermediate layer (HTL) and the electron transport intermediate layer (ETL) $[76,77]$ due to their considerable charge transport capabilities and appropriate energy levels. Currently, considerable effort has been expended to develop various ETLs and HTLs materials for achieving OPVs with better performance.

\subsection{Multicomponent OPVs with BHJ Structure}

To date, the reported multicomponent-based OPVs can be divided into ternary OPVs and quaternary OPVs, which contain three and four components in active layers, respectively. On the basis of the role of the third component, ternary OPVs can be classified into two categories: one donor/two acceptors and two donors/one acceptor. In quaternary OPVs, the third and fourth component may play different roles in improving the performance of OPVs. The active layer morphology in the quaternary system is more complicated compared with binary or ternary OPVs. Generally, materials with complementary absorption spectra are selected to achieve the purpose of covering a wider photon collection range in the active layer [70,78]. In addition, whether the materials have similar energy levels also needs to be considered. The similar LUMO or HOMO levels of multiple donors or acceptors can prevent the formation of deep charge trapping, thereby allowing better charge transfer in multicomponent-based active layers $[79,80]$. At the same time, good compatibility between multiple components is beneficial for the morphology of active layers, which is a factor worth considering. Many articles have shown that donors or acceptors with similar molecular structures often have good compatibility [81,82]. In addition, the complementary photovoltaic parameters are important criteria for the manufacture of high efficiency ternary OPVs $[42,83]$. The appearance of versatile donor and acceptor will make the development of ternary OPVs more rapid and flexible.

\subsubsection{Working Mechanism in Multicomponents OPVs}

At present, there are four working mechanisms in multiple OPVs: energy transfer, charge transfer, alloy model and parallel-linkage [69]. Taking ternary dual donor system as an example, the working mechanism of a multicomponent system is introduced. The position of the third component in the active layer is closely related to the working mechanism of multicomponent-based OPVs, which is decided by the phase structure and energetics of the third component. As shown in Figure 7a, the third component might (i) be directly embedded into donor, (ii) form its own transport channels, (iii) locate at the interface of donor and acceptor or (iv) form an alloy state with the main donor [84]. For the charge transfer mechanism (Figure 7b), corresponding LUMO and HOMO energy levels of D2 are between those of A1 and D1. The third component should act as a bridge for facilitating the transport of holes to the anode and electrons to the cathode [85]. Energy transfer (Figure 7c) should be a competing process in comparison with the charge transfer among the materials. The charge transfer and energy transfer can occur simultaneously in blend films, but only one working mechanism is dominant. Efficient energy transfer requires substantial overlap between the emission spectrum of one component and the absorption spectrum of another component, as well as $<10 \mathrm{~nm}$ spacing between them. The energy transfer should provide a potential pathway to improve the utilization of excitons $[86,87]$. To explain the varied $V_{O C}$ of ternary OPVs along with the addition of third component, the parallel-linkage (Figure 7d) and alloy model (Figure 5e) were proposed. In the case of the parallel-linkage, ternary OPVs are similar to the parallel connections between subcells in a tandem architecture. Excitons generated in the donor migrate to the corresponding donor/acceptor interface and decompose into free electrons and holes. Electrons are transported through the corresponding acceptor matrix to the cathode, and holes are transported to the an- 
ode through a transport channel formed by the donor. There is no electronic interaction between two donors [88]. In the case of the alloy model, two donors are coupled into a new charge transfer state, which is determined by blend composition. Good compatibility among the materials used is generally required for the formation of the alloy model $[38,89]$.

(a)

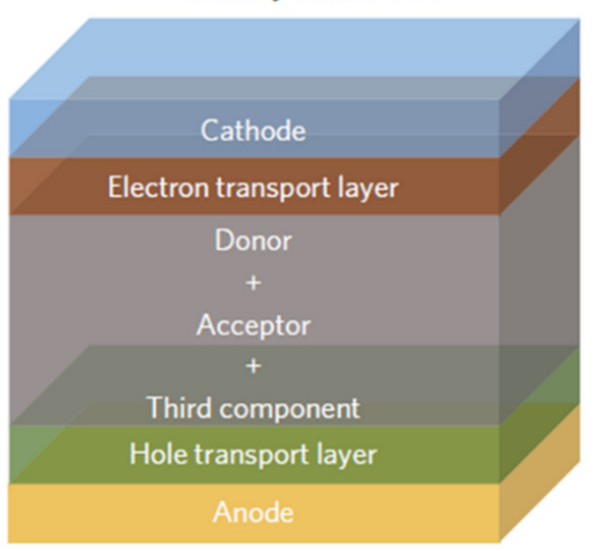

(b)

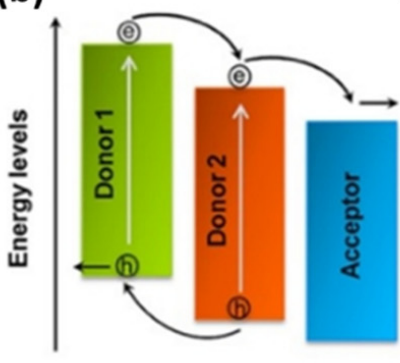

(c)

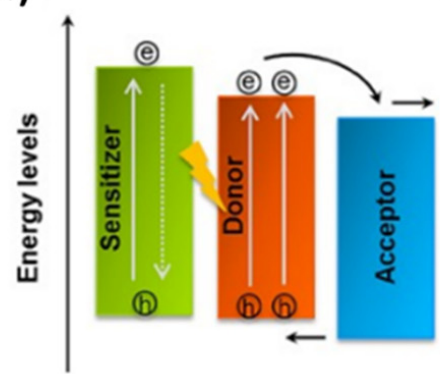

Embedded in one phase

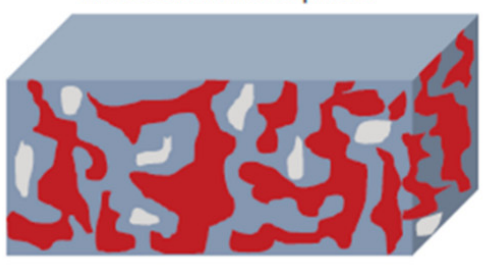

Located at interfaces

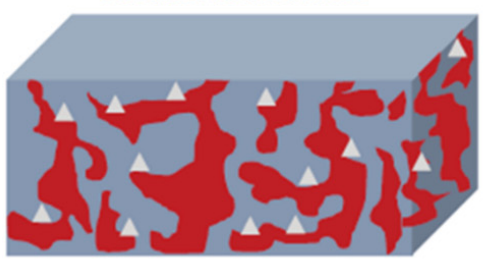

(d)

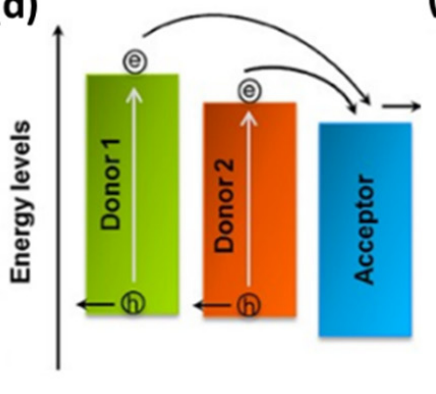

Parallel-like structure

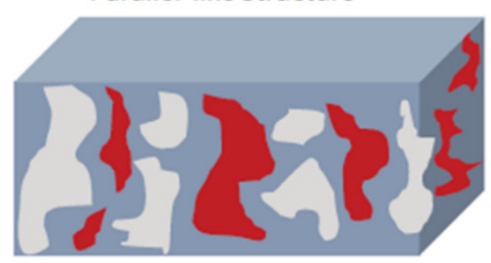

Alloy structure

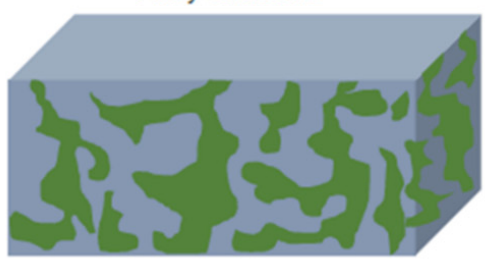

(e)

Figure 7. (a) Structures of ternary OPVs with four distribution patterns of the third component. Reproduced from [84]. Working principle diagram of ternary OPV based on double donors: (b) charge transfer, (c) energy transfer, (d) parallel-like mechanism and (e) alloy model. Reproduced from [90]. Reprinted with permission from ref. [84]. Copyright 2015 Nature Photonics; Reprinted with permission from ref. [90]. Copyright 2017 Wiley.

Recently, it was demonstrated that the proposed working mechanism can coexist in ternary OPVs. Different working mechanisms may be converted to each other along with varied content of active layer materials. Photoluminescence (PL) spectra, time-resolved transient photoluminescence (TRPL) spectra, $J-V$ curves based on neat donor or acceptor devices and cyclic voltammetry $(\mathrm{CV})$ curves should be popular and convenient tools to investigate and distinguish the corresponding working mechanism in ternary OPVs [91-93]. It was demonstrated that the distribution of the third component plays a vital role in determining the working mechanism of ternary OPVs. Recently, Zhang et al. proposed a new method to investigate compatibility among the used materials. In a PBDB-T-2Cl:Y6:PC ${ }_{71} \mathrm{BM}$ based system, the characteristic Raman peaks of $\mathrm{Y} 6$, PBDB-T-2Cl and $\mathrm{PC}_{71} \mathrm{BM}$ are 2219, 2960, and $259 \mathrm{~cm}^{-1}$, as shown in Figure 8a. Raman map of blend films can be drawn based on the Raman characteristic peak of required material, as shown in Figure 8b [94]. The blue, green and red areas correspond to $\mathrm{Y} 6, \mathrm{PC}_{71} \mathrm{BM}$ and $\mathrm{PBDB}-\mathrm{T}-2 \mathrm{Cl}$, respectively. According to the Raman images of the ternary blend film, most of the green dots are surrounded by blue dots, which reflect that $\mathrm{PC}_{71} \mathrm{BM}$ tends to mix with $\mathrm{Y} 6$, between the two materials. Raman technology has been applied in other ternary systems, such as PM6:Y6:MF1 [38] and PM6:IT-2F:T6Me [95], which can give intuitive evidence on the compatibility of the materials. 

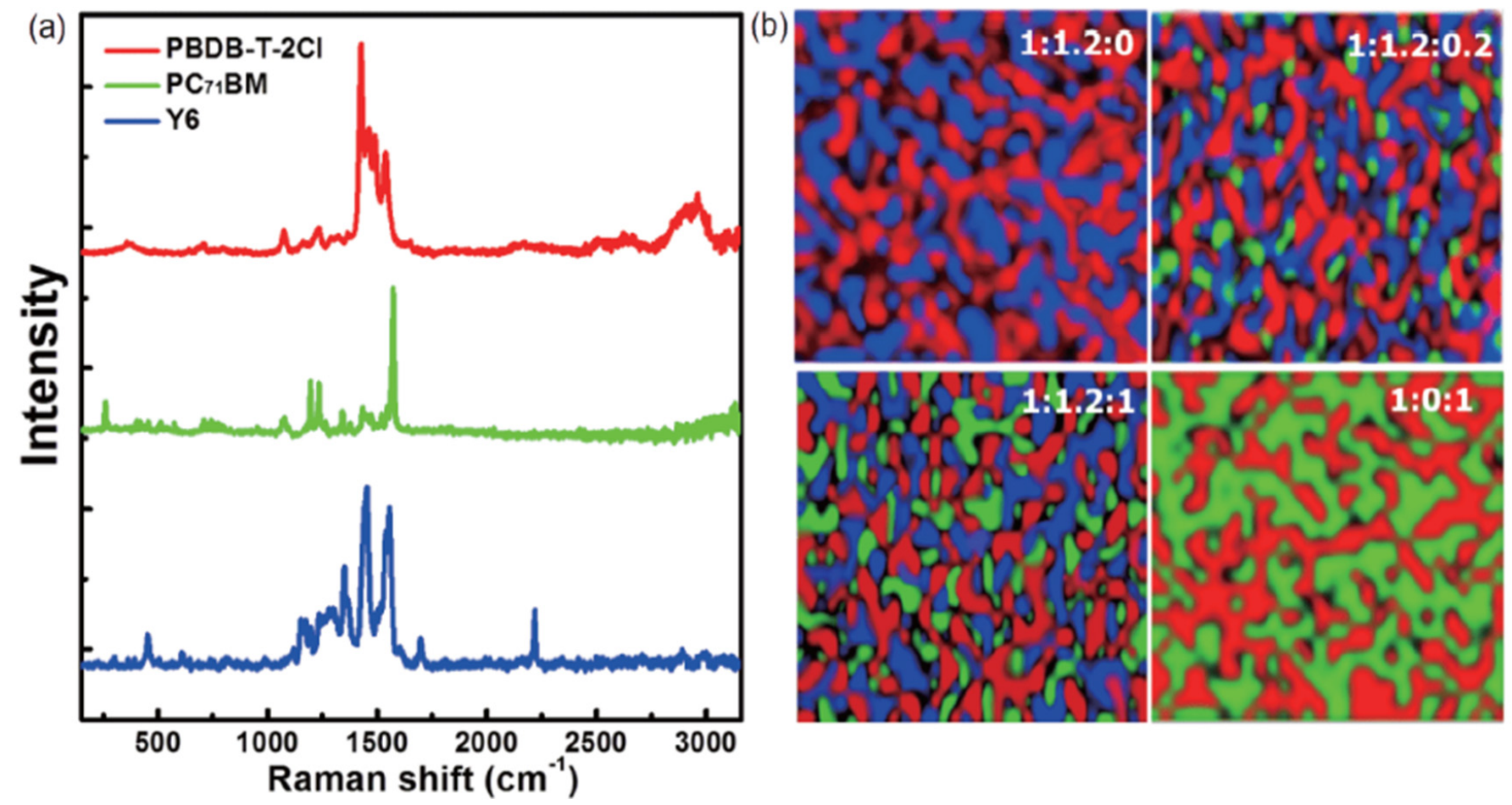

Figure 8. (a) Raman spectra of three materials: PBDB-T-2Cl, $\mathrm{PC}_{71} \mathrm{BM}$ and $\mathrm{Y} 6$; (b) Raman mapping image of ternary blend films with different $\mathrm{PC}_{71} \mathrm{BM}$ contents. Reproduced from [94]. Reprinted with permission from ref. [94]. Copyright 2019 Science China Chemistry.

\subsubsection{Typical Works on Ternary OPVs}

The combination of fullerene and NFAs is an efficacious means of selecting materials for fabricating ternary OPVs. In the past ten or more years, fullerene derivatives such as $\mathrm{PC}_{71} \mathrm{BM}$ or $\mathrm{PC}_{61} \mathrm{BM}$ have been extensively used as the acceptor for OPVs due to their advantages of large electron affinity, high electron mobility and anisotropic charge transport. On the contrary, fullerene derivatives have some disadvantages, such as the mismatched energy level and feeble absorption capacity with the donor, which leads to inadequate photon capture and odd voltage loss. In recent years, various NFAs have been designed and synthesized to fabricate OPVs due to their advantages of strong absorptivity in a particular range, low energy loss and tunable energy levels. In contrast, some blended films based on non-fullerene materials have large phase separation due to the strong crystallinity of NFAs. The association of fullerene and non-fullerene materials can actively solve the problem of poor morphology. Merits of fullerene and non-fullerene materials can be integrated into one cell through ternary strategy and result in performance preferable to that of OPVs based on an individual acceptor. The morphology and photon capture of active layers can be improved by mixing fullerene derivatives into a highly efficient binary system. In 2019, PC $_{71}$ BM was incorporated into PM6:Y6 system by Peng et al. "A PCE of $16.67 \%$ is realized in the optimized ternary OPVs with the weight ratio of PM6:Y6:PC ${ }_{71} \mathrm{BM}$ as 1:1.0:0.2." [96]. Obviously, the intensity of EQE spectra in the absorption range $300-500 \mathrm{~nm}$ is simultaneously increased along with the increase of $\mathrm{PC}_{71} \mathrm{BM}$ in acceptors, owing to enhanced photon capture by incorporating $\mathrm{PC}_{71} \mathrm{BM}$. Except for photon capture, the fullerene derivatives can also play the part of a morphology regulator for preferable charge transport and exciton dissociation in active layers. In 2020, Zhang et al. reported ternary OPVs with PM7:Y6:PC ${ }_{71} \mathrm{BM}$ as the active layer. "The EQE of ternary OPVs are almost impossibly enhanced in the strong absorption spectrum range of $\mathrm{PC}_{71} \mathrm{BM}$, indicating that extra $\mathrm{PC}_{71} \mathrm{BM}$ has negligible contribution on photon harvesting in the short wavelength range." [94]. To investigate the influence of extra $\mathrm{PC}_{71} \mathrm{BM}$ on morphology, GIWAXS and GISAXS characterizations were carried out. "The OOP (010) peak and IP 
(100) peak can be concurrently enhanced in the PM7:Y6:PC 71 BM (1:1.2:0.2, wt/wt) blend films, indicating the face-on orientation is more ordered in the optimum ternary blend films." [94]. There is, to emphasize, an IP (100) peak that is lightly shifted toward high $q$ values in pace with more addition of $\mathrm{PC}_{71} \mathrm{BM}$, meaning lamellar staking spacing gets closer in optimized ternary OPVs. The improved molecular arrangement can facilitate charge transport in active layers. On the basis of GISAXS of hybrid films, the domain size of donor and acceptor can be calculated. The domain sizes of acceptor and donors can be well regulated by mixing added $\mathrm{PC}_{71} \mathrm{BM}$. For ternary hybrid films, analogous domain size of acceptor and donors approach the exciton diffusion length of about $10 \mathrm{~nm}$, which is beneficial for efficient exciton dissociation in active layers. The $16.71 \%$ PCE is achieved in the PM7:Y6:PC 71 BM (1:1.2:0.2, wt/wt) based OPVs, rooting in the concurrently improved FF of $75.66 \%, J_{S C}$ of $25.44 \mathrm{~mA} \mathrm{~cm}^{-2}$, and the invariant $V_{O C}$ of $0.868 \mathrm{~V}$. Recently, Yang et al. designed a $\mathrm{Y} 6$ derivative named $\mathrm{Y} 6-\mathrm{C} 2$ by moving the branching points of the alkyl chains on the nitrogen atom [97]. The PCE of $15.89 \%$ was achieved when blending Y6-C2 with PM6 as active layers. The $\mathrm{PC}_{71} \mathrm{BM}$ was chosen as the third component due to its good compatibility with Y6-C2. The $17.06 \%$ PCE was achieved when the mass ratio of Y6-C2: $\mathrm{PC}_{71} \mathrm{BM}$ was 1.0:0.2, along with $V_{O C}$ of $0.859 \mathrm{~V}, J_{S C}$ of $25.73 \mathrm{~mA} \mathrm{~cm}^{-2}$ and FF of $77.2 \%$.

Contrasted with fullerene and non-fullerene-based OPVs, non-fullerene OPVs exhibit more elastic composition modification, providing plenty of chances for improving the performance of OPVs. Absorption spectra, optical bandgap and energy levels of ternary blend films are more widely modulated by two NFAs. Meanwhile, NFAs with similar chemical structures might show good compatibility, which is a considerable element in deciding the phase separation degree and dynamic processes. In this situation, ternary OPVs with two compatible NFAs have attracted much attention in the latest years. In 2019, Zhang et al. reported ternary OPVs based on a newly synthesized NFA 3TP3T-4F and PM6:Y6 system [82]. The compatibility among the materials used was intensively investigated according to a series of characterization methods. According to atomic force microscope (AFM) images, surface morphology and phase separation degree of hybrid films were hardly affected by incorporating 3TP3T-4F as the third component. Measurement of water contact angles (WCAs) for PM6, Y6 and 3TP3T-4F was carried out. The surface tensions $(\gamma)$ of different materials were $23.3,25.0$ and $25.7 \mathrm{mN} \mathrm{m}^{-1}$ for PM6, Y6 and 3TP3T-4F. The compatibility of two different materials was assessed by applying the equation $\chi \propto\left(\sqrt{\gamma_{A}}-\sqrt{\gamma_{B}}\right)^{2}$, in which $\chi$ represents the Flory-Huggins interaction parameter. The $\chi$ parameter between Y6 and 3TP3T- $4 \mathrm{~F}$ is calculated to be 0.0049 , indicating excellent compatibility between $\mathrm{Y} 6$ and 3TP3T-4F. "To further examine the effect of incorporating 3TP3T-4F on charge separation in active layers, the reorganization energy $(\lambda)$ was calculated based on the global analysis of the measured Fourier-transform photocurrent spectroscopy, EL spectra and external quantum efficiency (FTPS-EQE), as shown in Figure 9a-e." [82]. The values of $\lambda$ are 0.066 and 0.081 for PM6:Y6:3TP3T-4F and PM6:Y6 based OPVs, respectively. The slightly reduced reorganization energy at the donor/acceptor interface resulting from incorporation of an appropriate amount of 3TP3T- $4 \mathrm{~F}$ is beneficial to interfacial charge dissociation and transfer in the active layer. PCE of $16.7 \%$ is realized when mixing $15 \mathrm{wt} \%$ 3TP3T-4F in acceptors, resulting from concurrently increased $V_{O C}$ of $0.85 \mathrm{~V}, J_{S C}$ of $25.9 \mathrm{~mA} \mathrm{~cm}^{-2}$ and $\mathrm{FF}$ of $74.9 \%$. In 2020, Zhang et al. reported ternary OPVs with compatible PM6 as a donor, and MF1 and Y6 as acceptors [38]. "The PCE of $17.22 \%$ (certified 16.8\%) is realized when mixing $10 \mathrm{wt} \%$ MF1 in acceptors, along with $V_{O C}$ of $0.853 \mathrm{~V}, J_{S C}$ of $25.68 \mathrm{~mA} \mathrm{~cm}{ }^{-2}$ and FF of $78.61 \%$." [38].

It is common knowledge that the $V_{O C}$ of OPVs mainly are decided by the energy level difference between LUMO of acceptor and HOMO of donor, and energy loss $\left(E_{\text {loss }}\right)$. In 2019, Zhan et al. proposed a "voltage-increased" approach by employing a second acceptor, which is structurally similar and has a higher LUMO level compared to the host. A PCE of $16.1 \%$ is reported by Zhan et al. in PBDB-T-SF:Y6:ITCT based ternary OPVs [98]. The calculated LUMO energy levels of $Y 6$ and ITCT are $-4.15 \mathrm{eV}$ and $-3.92 \mathrm{eV}$, respectively. In comparison with Y6, the ITCT:Y6 mixtures with mass ratios of 1:0.5, 1:0.2, and 1:0.1 exhibit higher LUMO energy levels of $-4.03,-4.06$, and $-4.08 \mathrm{eV}$. $V_{O C} \mathrm{~s}$ of OPVs 
are improved with the increase of ITCT, resulting from uplifted LUMO energy levels by incorporating ITCT. In addition to energy level, the compatibility of the materials used is another consideration for selecting the third component. ITCT and Y6 show homologous structure, which is better for maintaining the film morphology of the host binary. PCE of $16.4 \%$ is obtained when the weight ratio of D1/A1/A2 is 1:1.1:0.1, resulting from simultaneously improved $V_{O C}$ of $0.885 \mathrm{~V}$ and FF of $73.67 \%$.

(a)

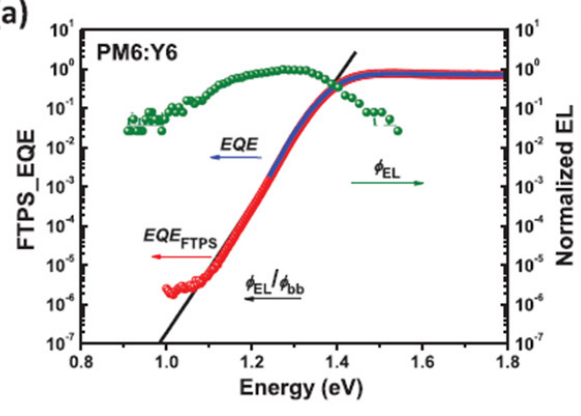

(b)

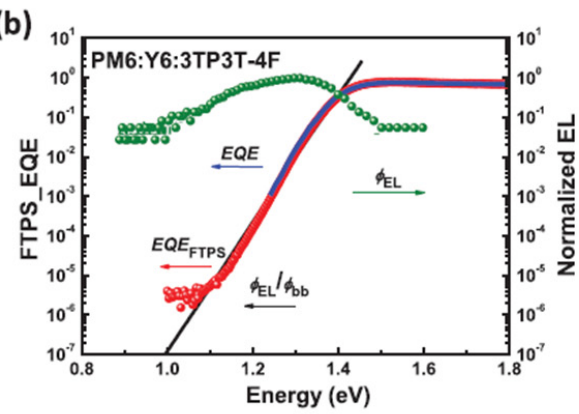

(c)

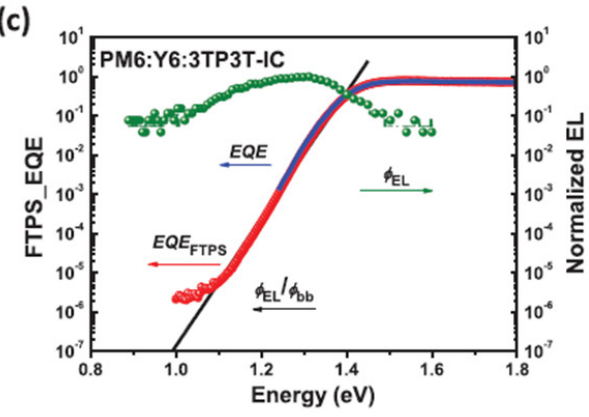

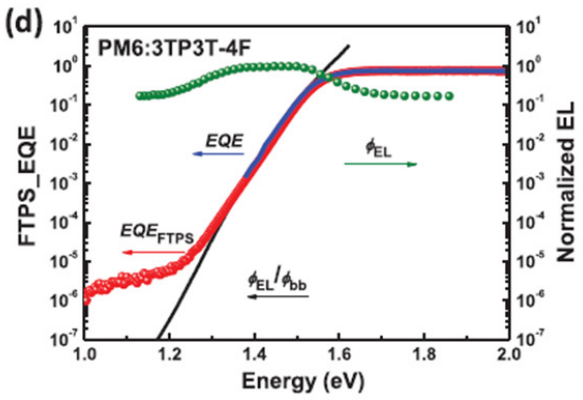

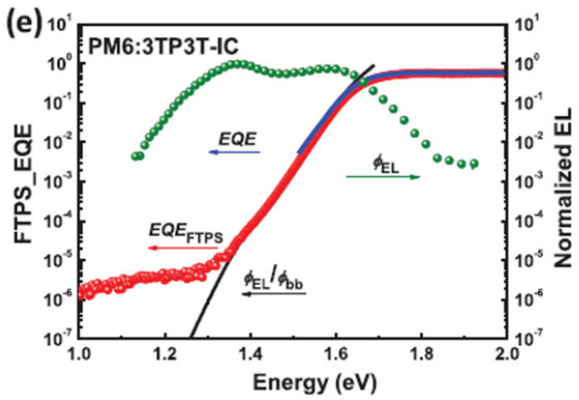

Figure 9. (a-e) Intensity of FTPS-EQE and their fitting. Reproduced from [82]. Reprinted with permission from ref. [82]. Copyright 2019 Wiley.

"The $E_{\text {loss }}$ is unavoidable in photoelectric conversion processes involving organic semiconducting materials, which is affected by two key elements. One element is the driving force for charge generation, which is interpreted as the shift between the bandgap of the donor/acceptor materials and the energy of the charge transfer (CT) state." [99], as shown in Figure 10a. The schematic of two charge-generation pathways in systems with large offset energy is shown in Figure 10b. "The charge can emerge in systems with a large offset energy such that the difference between the lowest singlet exciton energy (S1 or equivalently Eg) and the charge transfer state (ECT) is greater (case A) or less (case B) than the long-range Coulomb potential (W), which demands to be overcome in order to separate charge and create free carriers beyond their Langevin recombination radius $(>5 \mathrm{~nm})$. For low $E_{\text {loss }}$ systems, case B will be predominant. Free carriers can be produced from localized CT states either by thermal promotion to delocalized states or by successive hopping." [99]. A comparatively small driving force takes precedence over realizing rapid and active charge separation. Another element influencing $E_{\text {loss }}$ is non-radiative recombination, which can be geminate or non-geminate. The $E_{\text {loss }}$ can be divided into three parts based on the Shockley-Queisser (SQ) limit:

$$
\begin{array}{cc}
E_{\text {loss }} & =E_{g}-e V_{O C} \\
& =\Delta E_{1}+\Delta E_{2}+\Delta E_{3} \\
& =\left(E_{g}-e V_{O C}^{S Q}\right)+\left(e V_{O C}^{S Q}-e V_{O C}^{R a d}\right)+\left(e V_{O C}^{R a d}-e V_{O C}\right)
\end{array}
$$



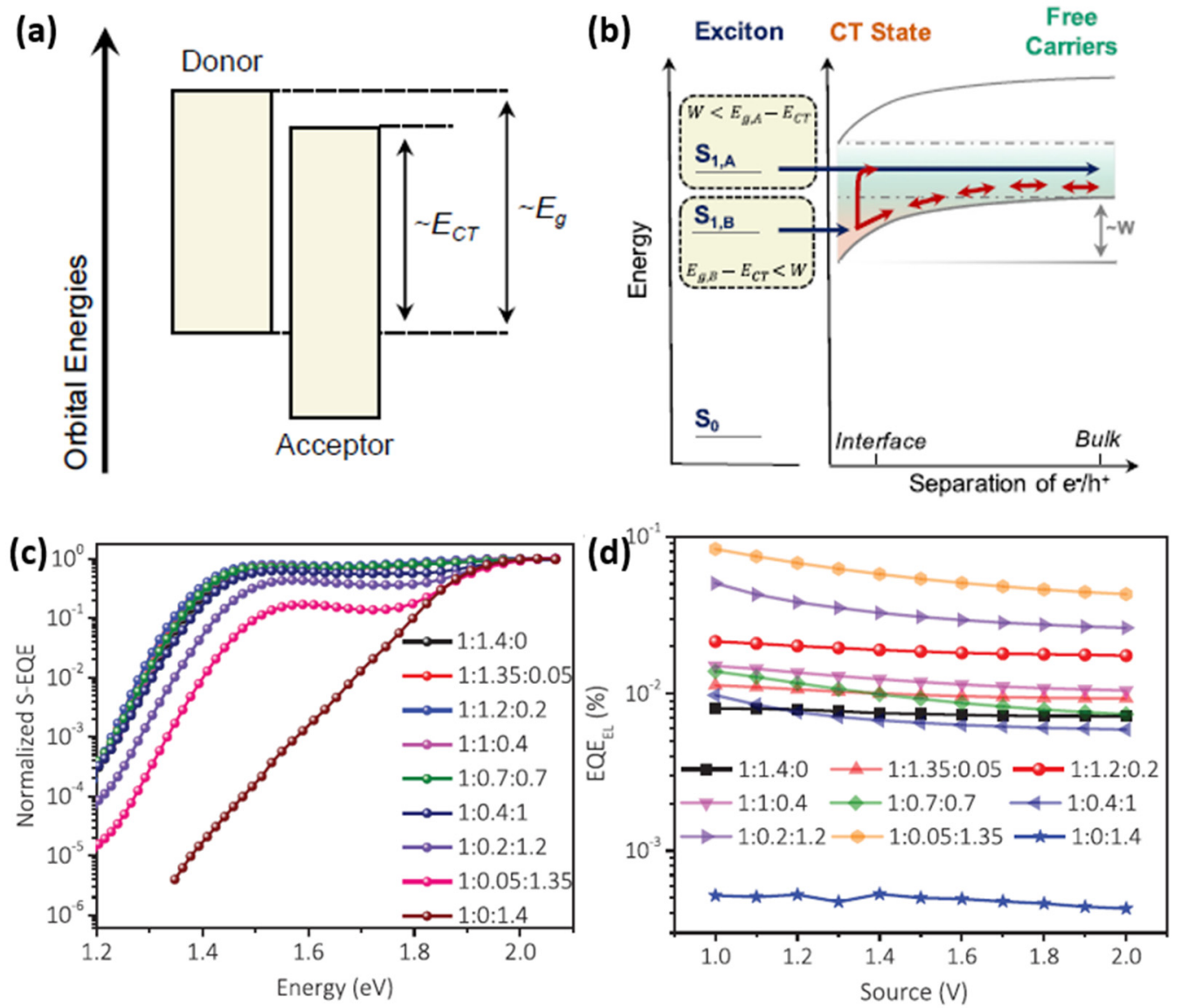

Figure 10. (a) Diagram of organic solar cell orbital energetics for a typical donor-acceptor pairing. (b) Schematic of two charge-generation pathways in systems with a large offset energy. Reproduced from [99]. (c) Normalized s-EQEs and (d) $\mathrm{EQE}_{\mathrm{EL}}$ values of the binary and ternary devices. Reproduced from [100].

"In this formula, $\Delta E_{1}$ means inevitable radiative recombination loss above the bandgap, which represents the difference between $E_{g}$ and maximum voltage $V_{O C}^{S Q}$ based on the SQ limit." [39]. $\Delta E_{2}$ represents radiative recombination loss below the bandgap, and $V_{O C}^{R a d}$ is the voltage when premeditating the actual radiative recombination. $\Delta E_{3}$ means nonradiative loss, which is linearly bound with the natural logarithm of $E Q E_{E L}$, as represented by $\Delta E_{3}=-K T \ln \left(E Q E_{E L}\right)$. Minimizing $E_{\text {loss }}$ with ternary strategy is now an emergent channel for achieving performance improvement of OPVs. In 2019, Hou et al. reported the reduced $E_{\text {loss }}$ of ternary OPVs by mixing fullerene-derived $\mathrm{PC}_{61} \mathrm{BM}$ as the third component into the PM6:Y6 system [100]. PCE of $16.5 \%$ is realized in the optimized ternary OPVs, along with $V_{O C}$ of $0.845 \mathrm{~V}, J_{S C}$ of $25.4 \mathrm{~mA} \mathrm{~cm}^{-2}$, and $\mathrm{FF}$ of $77 \%$. The optimized ternary OPVs with a mass ratio of PM6:Y6: $\mathrm{PC}_{61} \mathrm{BM}$ of 1:1.2:0.2 showed the largest $\mathrm{EQE} \mathrm{EL}_{\mathrm{EL}}$ of $1.9 \times 10^{-4}$, as shown in Figure 10c,d. The calculated $\Delta E_{3}$ is $0.25 \mathrm{eV}, 0.22 \mathrm{eV}$ and $0.32 \mathrm{eV}$ for the PM6:Y6, optimized ternary and $\mathrm{PM6}: \mathrm{PC}_{61} \mathrm{BM}$ devices, respectively, indicating the reduced non-radiative recombination by employing ternary strategy. In 2020, Zhang et al. reported ternary OPVs with PM6:BTP-4F-12:MeIC as the active layer [39]. A PCE of 17.4\% is realized when mixing $15 \mathrm{wt} \%$ MeIC in acceptors, resulting from $\mathrm{FF}$ of $79.2 \%, V_{\mathrm{OC}}$ of $0.863 \mathrm{~V}$ and $J_{S C}$ of $25.4 \mathrm{~mA} \mathrm{~cm}{ }^{-2}$. "Photon harvesting, exciton dissociation and charge transport of ternary active layers can be synergistically improved by mixing $10 \mathrm{wt} \% \mathrm{MeIC}$ in acceptors." [39]. At the same time, the minimized $E_{\text {loss }}$ of $0.526 \mathrm{eV}$ can be realized in the PM6:BTP-4F-12:MeIC(1:1.08:0.12, wt/wt) based OPVs, leading to enhanced $V_{\mathrm{OC}}$ of ternary OPVs. The detailed $E_{\text {loss }}$ of blend OPVs was further studied by $\mathrm{EQE}_{\mathrm{EL}}$ spectra and highly sensitive EQE (s-EQE) spectra. The addition of MeIC did not bring about any extra absorption or emission of subgap states, causing $\Delta E_{2}$ of ternary OPVs to approach 
the BTP-4F-12 based ternary OPVs. The ternary OPVs exhibit an EQE $\mathrm{EL}_{\mathrm{E}}$ of $1.58 \times 10^{-4}$, which is higher than those of two binary OPVs, resulting in reduced non-radiative loss of $0.227 \mathrm{eV}$. Reduced non-radiative loss might cause performance improvement of PM6:BTP4F-12:MeIC(1:1.08:0.12, wt/wt) based OPVs.

In comparison with the polymer/small molecule blend systems, all-polymer based OPVs consisting of tightly entangled polymer acceptor and donor, tend to possess better operational lifetime due to their outstanding morphological and device stabilities under mechanical and thermal stresses. In 2021, Min et al. designed a near-infrared polymer acceptor $\left(P_{\mathrm{A}}\right)$ PY2F-T, and the all-polymer solar cells (all-PSCs) achieved a 15.0\% PCE by blending PM6 as the donor [37]. Subsequently, PYT was incorporated into the PM6: PY2F-T main system as the third component. The PM6:PY2F-T:PYT based all-PSCs achieved $V_{\mathrm{OC}}$ of $0.90 \mathrm{~V}, J_{\mathrm{SC}}$ of $25.2 \mathrm{~mA} \mathrm{~cm}^{-2}$, FF of $76 \%$ and a high PCE of $17.2 \%$ (certified PCE of $16.9 \%$ ). Contrasted with the PM6:PY2F-T system, the ternary OPVs exhibits lower energy loss, better light absorption and light thermal stability. This work promotes the development of high-performance ternary all-PSCs and creates possibilities for their application.

\subsubsection{Typical Works on Quaternary OPVs}

Ternary strategy has been proved to be an efficient means to improve the performance of OPVs by mixing a donor or acceptor into the host binary system. Building on the foundation of ternary OPVs and to pursue highly efficient OPVs, more attempts such as quaternary strategy emerged for utilizing multicomponents with a complementary absorption spectrum. The third and fourth components can work independently to optimize performance of OPVs step-by-step, which further explores the potential of materials. In general, photon harvesting, photogenerated exciton distribution, exciton dissociation and charge transport in quaternary active layers can be individually or simultaneously improved by successively mixing the desirable third or fourth component. It should be noted that the dynamic process of excitons and charge carriers is exceptionally complicated, involving four functional components in active layers, which makes the selection of appropriate active layer materials very challenging. Before 2019, quaternary OPVs with more than $14 \%$ PCE had never been realized, which was far behind the development of ternary OPVs. Generally, a quaternary OPV is composed of two fullerene derivatives and one NFA. Actually, choosing fullerene derivatives as the third and fourth components in quaternary OPV may not be an ideal strategy. The fullerene derivatives may be the outstanding fourth component based on favorable ternary non-fullerene OPVs.

Benefiting from the rapid development of highly efficient active materials, over $16 \%$ PCE is realized in quaternary OPVs. In 2020, Zhang et al. reported highly efficient quaternary OPVs with PM6:Y6:Br-ITIC:PC 71 BM as the active layer [101]. "A PCE of $15.7 \%$ is realized in the PM6:Y6 based binary OPVs, along with $V_{O C}$ of $0.841 \mathrm{~V}, J_{S C}$ of $25.2 \mathrm{~mA} \mathrm{~cm}^{-2}$, and $\mathrm{FF}$ of $74.3 \%$. The PCEs of $16.4 \%$ and $16.2 \%$ can be achieved by mixing a suitable amount of $\mathrm{PC}_{71} \mathrm{BM}$ and Br-ITIC as the third component, respectively, corresponding to the $J_{S C}$ of 25.6 vs. $25.5 \mathrm{~mA} \mathrm{~cm}^{-2}, V_{O C}$ of 0.836 vs. $0.854 \mathrm{~V}$ and $\mathrm{FF}$ of $75.6 \%$ vs. $75.1 \% . "$ [101]. Based on optimized ternary OPVs, $\mathrm{PC}_{71} \mathrm{BM}$ is mixed as a morphology regulator to commendably improve phase separation and molecular arrangement of the active layer of the mixed film, resulting in an improved PCE of $16.8 \%$ with further marginally increased FF of $76.4 \%$ and $J_{S C}$ of $25.8 \mathrm{~mA} \mathrm{~cm}^{-2}$. The drop of EQE spectrum for the PM6:Y6 based binary OPV in the wavelength range of 650 to $800 \mathrm{~nm}$ can be gradually compensated by continuously adding suitable amounts of $\mathrm{Br}$-ITIC and $\mathrm{PC}_{71} \mathrm{BM}$, which can be clearly observed from the amplified EQE spectrum. The optimized phase separation in the quaternary active layer improves exciton dissociation and charge transport, resulting in enhanced EQE values in the long wavelength range. "The optical field distribution in OPVs and photogenerated exciton density in active layers were simulated by using the transfer matrix method" [101], as shown in Figure 11a-f. The calculated values of photogenerated exciton density are $3.52 \times 10^{29}, 3.47 \times 10^{29}$ and $3.46 \times 10^{29} \mathrm{~s}^{-1} \mathrm{~m}^{-3}$ in the quaternary, ternary and binary blend films, which supports the $J_{S C}$ improvement of ternary OPVs. "The hole and electron 
produced in the middle region are likely to be simultaneously collected by the electrode because of their similar transport distance. Here, the calculated photogenerated exciton density values in the middle $50 \mathrm{~nm}$ region of active layer are $2.22 \times 10^{29}, 2.20 \times 10^{29}$ and $2.18 \times 10^{29} \mathrm{~s}^{-1} \mathrm{~m}^{-3}$ in the optimized quaternary, ternary and binary active layers." [101]. Enhanced photogenerated exciton density in the near-middle region of the ternary active layers should be beneficial to balance charge collection and transport. According to the space-charge limited-current (SCLC) method, the charge transport property was further investigated. The $\mu_{h} / \mu_{e}$ ratio decreased from 5.0 to 1.9 and 1.2 by successively incorporating Br-ITIC and $\mathrm{PC}_{71} \mathrm{BM}$. By mixing suitable $\mathrm{Br}$-ITIC and $\mathrm{PC}_{71} \mathrm{BM}$ into blend films, a gradually balanced charge transfer was realized, which is conducive to the gradual improvement of FF.
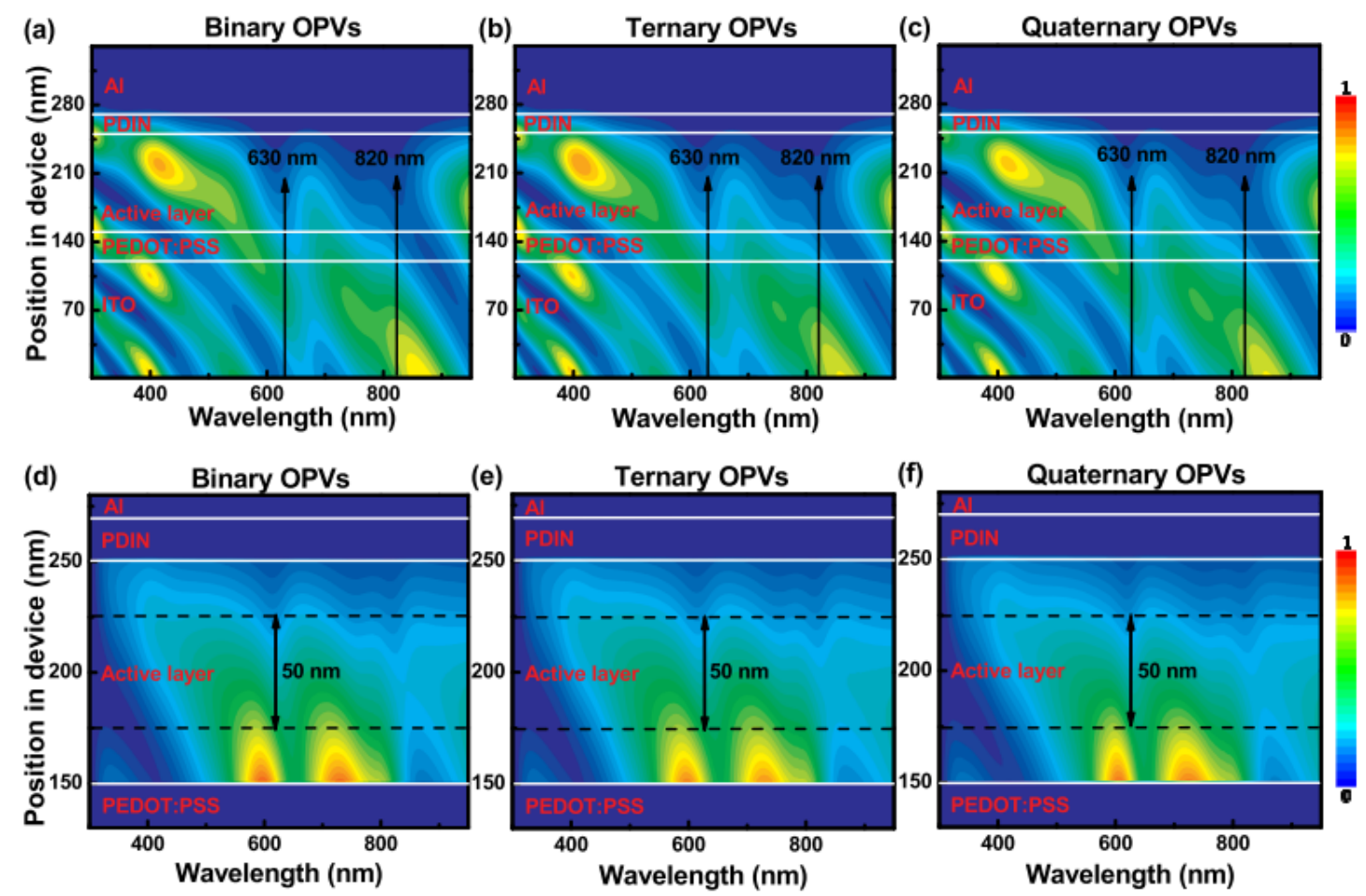

Figure 11. The simulated optical field distribution in the (a) binary, (b) ternary and (c) quaternary OPVs; calculated photogenerated exciton distribution in the optimized active layers of (d) binary, (e) ternary and (f) quaternary OPVs. Reproduced from [101]. Reprinted with permission from ref. [101]. Copyright 2020 Elsevier.

In the same year, another efficient quaternary OPV was reported by Zhan et al., developed by incorporating a newly synthesized polymer donor material PhI-Se and commonly used fullerene derivative $\mathrm{PC}_{71} \mathrm{BM}$ into an efficient binary system PM6:Y6 [51]. Solid-state ${ }^{19} \mathrm{~F}$ magic angle spinning nuclear magnetic microscopy $\left({ }^{19} \mathrm{~F}\right.$ MAS NMR), GIWAXS, elemental TEM mapping and transient absorption spectroscopy on corresponding films were carried out to investigate molecular structures and charge separation dynamic processes in active layers. In this quaternary system, Se is selectively decorated on PhI-Se, N is seen on PhI-Se and Y6, and F is modified on PM6 and Y6. Overlapping plots of the N and Se, F and Se, and N + F + Se mapping data (Figure 12) indicate that the incorporated PhI-Se prefer to form individual PhI-Se phases, which are interpenetrating with the PM6 and Y6 phases. The individual PhI-Se phase can enhance solar light absorption and function as additional paths for charge separation and hole transport. According to ${ }^{19}$ F MAS NMR spectroscopy and GIWAXS characterization results, the long-ranged structural order of acceptor phases can be improved by incorporating PhI-Se, which is beneficial to electron transport. A maximum PCE of $17.2 \%$ can be achieved in quaternary OPVs with the weight ratios of PhI-Se:PM6:Y6:PC ${ }_{71} \mathrm{BM}$ as 0.15:1:1.2:0.20. Recently, a 17.73\% PCE of quaternary OPVs was 
reported by Zhang et al. by using two polymer donors (PM6 and PTQ10) and two acceptors (N3 and $\mathrm{PC}_{71} \mathrm{BM}$ ) as the active layer [53]. The small domains of PTQ10 and $\mathrm{PC}_{71} \mathrm{BM}$ play the role of separators to spatially separate PM6 and N3, forming a "rivers-and-streams"like morphology. The hierarchical morphology can create respective pathways for both holes and electrons to transport across the active layer with suppressed recombination losses. Currently, the occurrence of highly efficient quaternary OPVs suggests that the development of quaternary OPVs can be gradually compared with that of binary and ternary OPVs. With careful material selection and morphology control, quaternary strategy can also play a key role in performance improvement of OPVs.
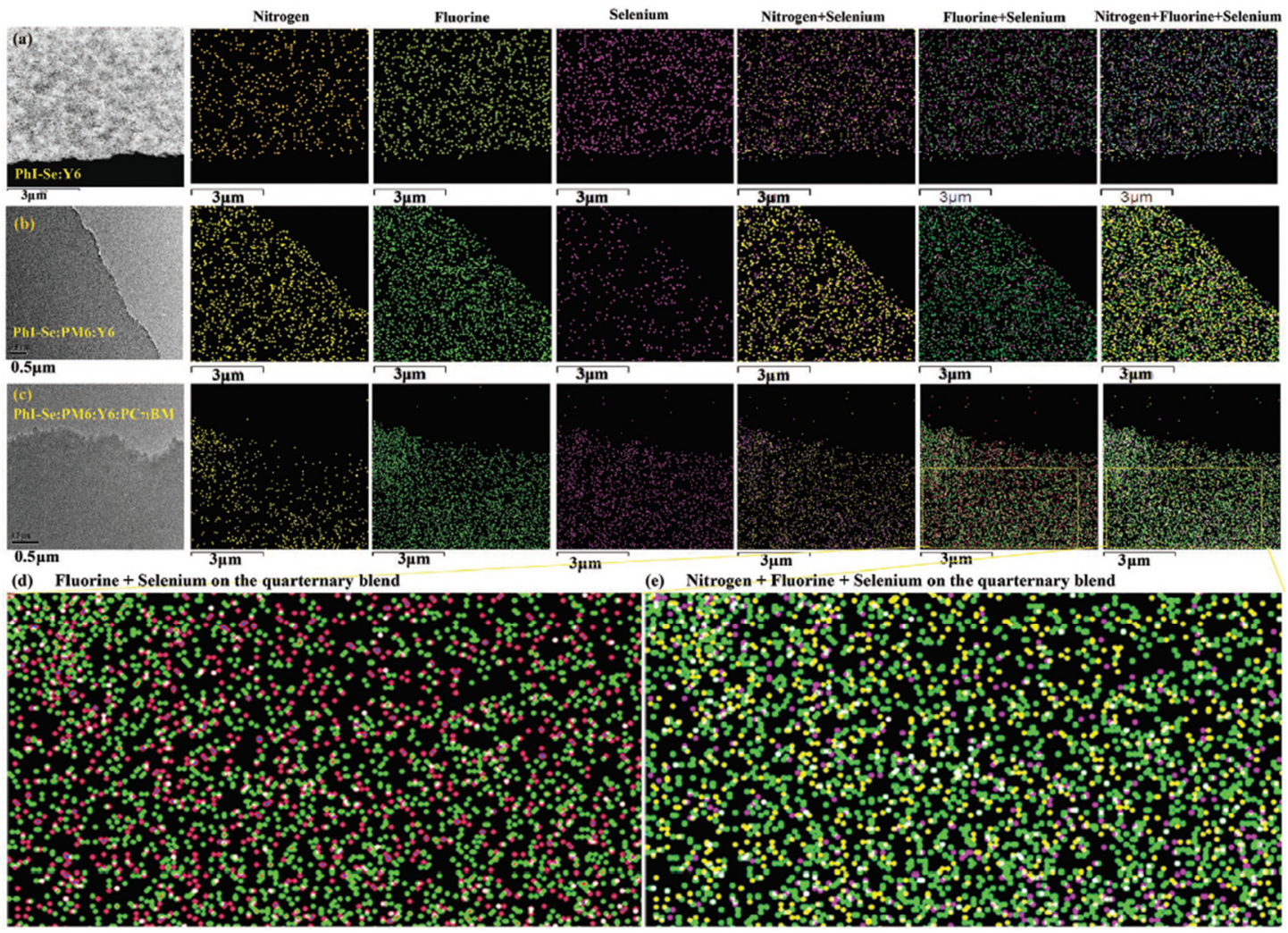

Figure 12. (a-c) Distribution of N, F and Se; (d,e) enlarged pictures. Reproduced from [51]. Reprinted with permission from ref. [51]. Copyright 2020 Wiley.

\subsection{Tandem Structure OPVs}

Based on the Shockley-Queisser (SQ) assumptions, there are two main losses in single junction OPVs: thermalization loss due to photons of higher energy than the bandgap and transmission loss resulting from low energy photons beyond the organic semiconducting material optical band edge [102,103]. An effective strategy to overcome the SQ limits is to construct tandem OPVs. Tandem OPVs are, in general, made of different bandgap materials to prepare double or multiple active layers connected by the middle electrode. Based on the connection methods of the subcells, the tandem OPVs can be divided into two categories: series and parallel tandem structures. The series tandem OPVs are designed to exhibit increased $V_{O C}$ values, which correspond to the sum of the $V_{O C}$ values for each subcell. The parallel tandem OPVs are prepared in order to obtain enhanced $J_{S C}$, which is equivalent to the sum of the $J_{S C}$ of each subcell.

Tandem strategy has emerged as an active means to achieve the performance improvement of OPVs. A series of successful works have been completed by many research groups. Especially, in 2018, Chen et al. reported a record and certified PCE of $17.29 \%$ for 2-terminal (2T) monolithic solution-processed tandem OPVs [104]. The semi-empirical analysis was carried out by Chen et al. for the possible PCE limit of $2 \mathrm{~T}$ tandem OPV cells 
under AM 1.5G illumination. Based on the model analysis, $\mathrm{CO}_{\mathrm{i}} 8 \mathrm{DFIC}$ was selected as the acceptor of the rear subcell due to its infrared absorption onset of $\sim 1050 \mathrm{~nm}$ (optical bandgap $\left.E_{g} 1.20 \mathrm{eV}\right)$. The PTB7-Th:CO $\mathrm{CO}_{\mathrm{i}} 8 \mathrm{DFIC}: \mathrm{PC}_{71} \mathrm{BM}$ based single junction OPVs exhibit a high $J_{S C}$ of $27.98 \mathrm{~mA} \mathrm{~cm}^{-2}, \mathrm{FF}$ of $69.7 \%, V_{O C}$ of $0.69 \mathrm{~V}$ and rather low $E_{\text {loss }}$ of $0.51 \mathrm{eV}$. The PBDB-T and F-M were selected as the donor and acceptor of the active layer of the front cell, which led to the absorption onset of the active layer mixture approaching $720 \mathrm{~nm}$. The PBDB-T:F-M based single junction OPVs show $V_{O C}$ of $0.94 \mathrm{~V}, J_{S C}$ of $15.96 \mathrm{~mA} \mathrm{~cm}^{-2}$, and $\mathrm{FF}$ of $69.8 \%$. It is known that the high and balanced $J_{S C}$ is one of the preconditions for fabricating efficient $2 \mathrm{~T}$ tandem OPVs. A remarkable PCE of $17.36 \%$ (certified $17.29 \%$ ) can be achieved in the optimized $2 \mathrm{~T}$ tandem OPVs, with $J_{S C}$ of $14.35 \mathrm{~mA} \mathrm{~cm}^{-2}, V_{O C}$ of $1.642 \mathrm{~V}$ and FF of $73.7 \%$.

Except for the selection of complementary active layer materials for harvesting more photons, the middle layer between two or more subcells is another key component for constructing efficient tandem OPVs. The middle layer (also called interconnecting layer) is a combination of an ultrathin hole extraction layer and electron extraction layer. An ideal middle layer should pass light and sustain the photocurrent by providing an optically transparent electrical contact for recombination of holes and electrons from the adjacent active layers [105]. In addition, the middle layer should provide chemical protection for the front subcell against dissolution from the solution processing of the back. These requirements severely limit the selection of the middle layer, which makes it challenging for fabricating highly efficient and reproducible tandem OPVs. In 2020, a simple and highly compatible middle layer of PEDOT:PSS HTL (HSolar)/ZnO in an inverted tandem OPVs was reported by So et al. [106]. Compared to the traditional PEDOT:PSS Al 4083 (c-PEDOT), the HSolar possesses a superior wettability on the underlying non-fullerene active layer, leading to superior charge carrier extraction features of the middle layer. The tandem OPVs were fabricated by employing FTAZ:IT-M as the front cell and PTB7Th:IEICO- $4 \mathrm{~F}$ as the back cell. The optimized tandem OPVs present PCE of $14.7 \%$, with $V_{O C}$ of $1.65 \mathrm{~V}, J_{S C}$ of $14.6 \mathrm{~mA} \mathrm{~cm}^{-2}$ and FF of $61 \%$. To demonstrate the generality of the middle layer process, the middle layer process recipe was shared with other research groups. All of the double-junction tandem OPVs based on distinct active layers exhibited high repeatability in several different laboratories without a significant loss in $V_{O C}$ and FF. Among these tandem OPVs, the highest $16.1 \%$ PCE was achieved by using the front cell based on PBDB-T:F-M and the back cell based on PTB7-Th:IEICO-4F. To further demonstrate the versatility of the HSolar process, homo triple-junction OPVs were prepared using PTB7-Th:IEICO-4F as the active layer. Device architecture was ITO/ZnO/active layer/HSolar/ZnO/active layer/HSolar/ZnO/active layer/MoOx/Ag. Based on the transfer matrix model simulation, the optimum thickness of the front, middle and back cell should be approximately 50, 90, and $120 \mathrm{~nm}$, respectively. The PCE of optimized homo triple-junction OPVs reached $11.2 \%$, which is higher than $9.9 \%$ in the corresponding single junction OPVs. In 2021, Huang et al. developed an effective interconnect layer based on the structure of ZnO NPs: PEI/PEI/PEDOT: PSS [107]. The optimal thickness of the pre-cell in these tandem OPVs was reduced by increasing the proportion of NFAs in the active layers to inhibit charge recombination. Tandem OPVs were designed based on the structure ITO/PEDOT:PSS/front cell/ZnO NPs:PEI/PEI/PEDOT:PSS/back cell/PNDIT-F3N/Ag. The front cell was PM7:TfIF- $4 \mathrm{Cl}$, and the back cell was PCE10:CO 8 DFIC:PC 70 BM. Finally, the optimal PCE was $18.71 \%$ (certified by an accredited institute to be $18.09 \%$ ) with $J_{\mathrm{SC}}$ of $14.59 \mathrm{~mA} \mathrm{~cm}^{-2}, V_{\mathrm{OC}}$ of $1.64 \mathrm{~V}$ and $\mathrm{FF}$ of $78 \%$. The various syntheses of highly efficient NFAs together with matched polymer donors brings more opportunity for further development of tandem OPVs. So et al. simulated a tandem OPVs by employing FTAZ:IT-M and PM6:Y6 as front cell and back cell, respectively, predicting the possibility of tandem OPVs with a PCE over $22 \%$.

It is undeniable that tandem strategy shows great potential for further improving OPVs and pushing PCE to a new level. It should be also noted that the relatively complicated fabrication process of tandem OPVs still limits their future commercial application. 
Currently, another emerging tandem solar cell, IPOSCs, has recently attracted attention due to its simplified fabrication process. IPOSCs are constructed by employing a wide bandgap perovskite-based front cell and narrow bandgap organic-material-based rear cell. The organic materials can be dissolved in orthogonal solvents and then deposited on the perovskite layer without the existence of a recombination layer. Recent rapid development of narrow bandgap organic semiconductors provides various excellent candidates as the back cells. In 2019, He et al. used a polymer donor S1, an NFA Y6, together with PCBM to form a ternary $\mathrm{BHJ}$ layer [108]. The ternary organic BHJ layers were then integrated into the top layer of the perovskite to extend the NIR photo response up to $980 \mathrm{~nm}$. Finally, a record $J_{\mathrm{SC}}\left(28.06 \mathrm{~mA} \mathrm{~cm}^{-2}\right)$ for perovskite solar cells with a $1.6 \mathrm{eV}$ bandgap material was achieved based on single-junction structure. This result demonstrates that the IPOSCs have a huge potential to break the single-junction SQ efficiency limits.

\subsection{Interface Engineering in OPVs}

In addition to the development of donors or acceptors, interface engineering is also crucial for the preparation of high efficiency OPVs. In 2020, Zhang et al. developed an aliphatic amine group, functionalized PDI derivative (PDINN) as a cathode interlayer material (CIM) in the OPVs, and used stable metals (silver and copper) in the air as the top cathode [25]. Due to the presence of the aliphatic amine group, PDINN has a suitable dipole moment, thereby reducing the work function (WF) of air-stable metals (silver and copper). The hydrogen bonds can be formed between the secondary amine in the PDINN side chain and photovoltaic materials, leading to an excellent connection with the active layer. As compared to generally employed CIM PDINO, the PDINN has relatively good contact with NFA based active layers, relatively strong capacity to decrease metal cathode WFs, relatively high electrical conductivity $\left(5.0 \times 10^{-4} \mathrm{~S} \mathrm{~cm}^{-1}\right)$ and stronger charge collection ability. At the same time, OPVs based on PDINN show excellent tolerance to the variation of PDINN thickness when manufacturing devices. For example, when the PDINN thickness is expanded to $27 \mathrm{~nm}$, PCE of the devices remains above $15.0 \%$. What is impressive is that when the thickness of PDINN is increased to $38 \mathrm{~nm}$, FF remains at $74.09 \%$, which is very important for large-area manufacturing of OPVs. In addition, PDINN also has the advantages of easy synthesis and low cost in the laboratory. PM6:Y6 was employed as the active layer to prepare all OPVs. Finally, the PCE of the PDINO/Ag based device is $15.17 \%$, the $V_{\mathrm{OC}}$ is $0.821 \mathrm{~V}, J_{\mathrm{SC}}$ is $25.58 \mathrm{~mA} \mathrm{~cm}^{-2}$, and FF is $72.24 \%$. The maximum PCE of devices with the PDINN/Ag cathode is even higher, reaching 17.23\%. Compared with PDINO/Ag based devices, the significant increased efficiency in PDINN/Ag based devices is due to the substantial improvement in photovoltaic parameters: $V_{\mathrm{OC}}$ increased from 0.821 to $0.847 \mathrm{~V}$ and FF increased from $72.24 \%$ to $78.59 \%$. This result suggests that regulating interfacial contact with proper intermolecular interactions should be a feasible method to enhance the performance of thin-film OPVs.

PEDOT:PSS is a popular anode interface material because of its good film forming property and excellent optical transparency [109]. In 2020, Huang et al. introduced dopamine hydrochloride (DA. $\mathrm{HCl}$ ) into PEDOT:PSS, considering that there are excess sulfonic acid groups in the PSS of PEDOT:PSS [110]. The ion exchange reaction between PSS and DA. $\mathrm{HCl}$ produces PSS-DA. The PSS-DA segment has stronger intermolecular accumulation in PEDOT:PSS-DA, thus improving the aggregation of the PEDOT main chain and the electronic conductivity of PEDOT:PSS. Finally, by employing PEDOT:PSS-DA as an anode interface material instead of PEDOT:PSS, the PCEs of PM6:Y6, PBDB-T:ITIC and PM6:IDIC, and P3HT:PC61BM based OPVs were concurrently increased. The results show that incorporating amino derivatives into PEDOT:PSS is an effective method to improve the performance of OPVs.

In 2019, Anthopoulos et al. used liquid-exfoliated 2D transition metal disulfides $\left(\mathrm{WS}_{2}\right.$ and $\mathrm{MoS}_{2}$ nanosheets) as HTLs directly coated on transparent ITO electrodes to change WF without further treatment [33]. Initially, $\mathrm{WS}_{2}$ and $\mathrm{MoS}_{2}$ were exfoliated by using previously reported protocols, as shown in Figure 13a. Figure 13b presents absorption spectra of the 
extracted $\mathrm{WS}_{2}$ and $\mathrm{MoS}_{2}$ flakes in ethanol:water. "As-prepared $\mathrm{MX}$ s suspensions were spin-coated onto ITO without any further treatment (Figure 13c)." [33]. Subsequently, to investigate surface morphology of the ITO, AFM images were characterized as shown in Figure 13d. Among these two $\mathrm{MX}_{2}$ systems, ITO/WS 2 exhibited the smoothest surface topography. $\mathrm{WS}_{2}$ flakes became larger and thinner compared to $\mathrm{MoS}_{2}$. By combining $\mathrm{WS}_{2}$ HTLs with PBDB-T-2F:Y6 and PBDB-T-2F:Y6:PC ${ }_{71} \mathrm{BM} \mathrm{BHJ}$ systems, the greatest PCE of $15.8 \%$ and $17 \%$ OPVs can be achieved, respectively. After investigation, the good photonic structure and restrained recombination loss of $\mathrm{WS}_{2}$ based OPVs resulted in higher efficiency.

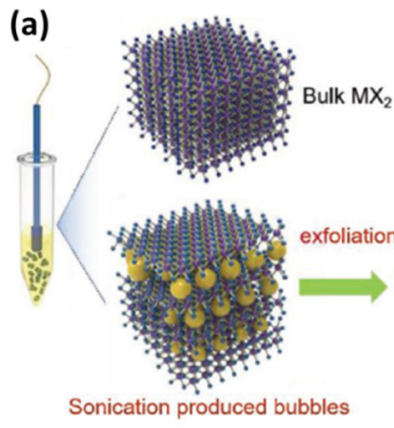

(c)

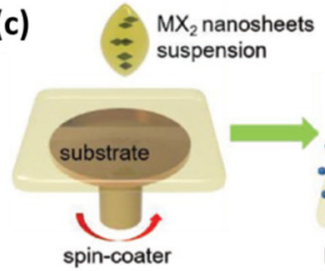

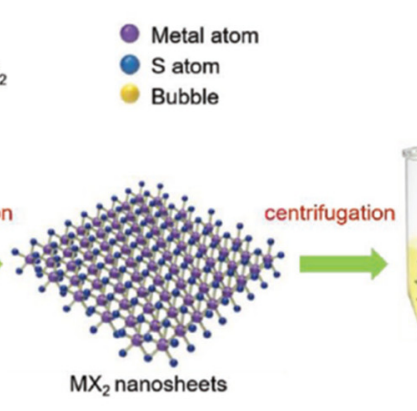

(d) (b)

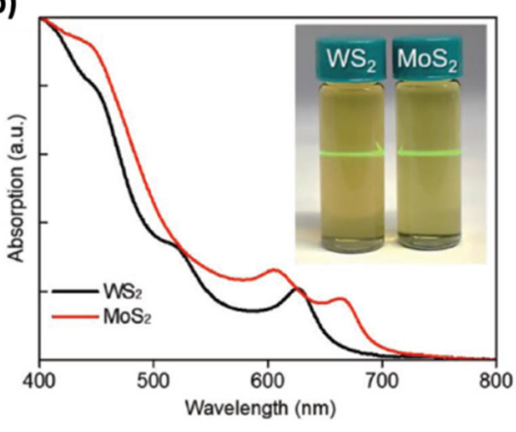

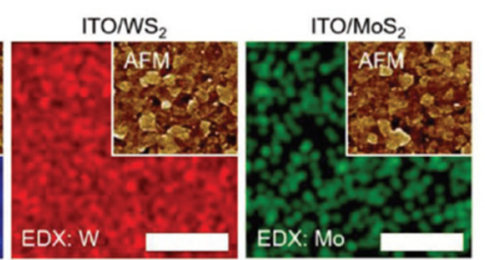

Figure 13. (a) The preparation process of $\mathrm{MoS}_{2}$ and $\mathrm{WS}_{2}$ suspensions. (b) Absorption spectra and the Tyndall effect in $\mathrm{WS}_{2}$ and $\mathrm{MoS}_{2}$ dispersions. (c) Schematic diagram of deposition of $\mathrm{MoS}_{2}$ and $\mathrm{WS}_{2} \mathrm{HTLs}$ on substrate. (d) Element mapping obtained using EDX (scale bar: $2 \mu \mathrm{m}$ ). Insets exhibit AFM images of corresponding samples. Reproduced from [33]. Reprinted with permission from ref. [33]. Copyright 2019 Wiley.

Polyoxometalate-based inorganic clusters (PICs) have the characteristics of easy preparation and purification of organic molecules and high WF of metal oxides. However, due to the limitation of quantum tunneling effect, the PIC film's hole transport ability is usually poor. In 2021, Hou et al. significantly enhanced the PICs' conductivity $\left(2.6 \times 10^{-3} \mathrm{~S} \mathrm{~m}^{-1}\right)$ on the basis of molybdenum and oxygen without influencing their relatively high WF property by mixing HPMO with bivalent tin (17:3) in methanol [111]. The chemical structure of HPMO is presented in Figure 14a. By employing HPMO as the HTL, the PM6:BTP-eC9 based OPVs presented a very low $0.25 \%$ PCE. "However, the device based on the HPMO:Sn (17:3) blend exhibited a high 17.3\% PCE, along with $V_{O C}$ of $0.84 \mathrm{~V}, J_{S C}$ of $26.8 \mathrm{~mA} \mathrm{~cm}{ }^{-2}$, and FF of 77\%, which were comparable to the best results for the PEDOT:PSS device." [111]. The $J-V$ curves and EQE spectra of corresponding devices are shown in Figure 14b,c. In order to study the HPMO:Sn's universality, PTB7-Th:PC ${ }_{71}$ BM, PBDB-T:ITIC and PM6:IT-4F were selected as the active layer to manufacture OPVs. Finally, the three OPVs' PCEs were comparable with their original PCEs reported in the literature, which indicates that HPMO:Sn can be generally used as HTL material. Furthermore, a $1.0 \mathrm{~cm}^{2}$ device (HPMO:Sn as HTL) made by the blade-coated method displayed a 15.1\% PCE (Figure 14d), which was the record-breaking value for large-area OPVs. Figure $14 \mathrm{~d}$ also presents the EQE mapping image, which indicates that about $80 \%$ of EQE is achieved. This result shows that $\mathrm{HPMO} \mathrm{Sn}$ is a high-performance HTL, which is low-cost, easy to prepare and compatible with a large-area printing process. 


\section{(a)}

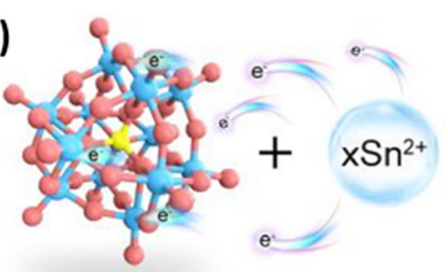

(b)

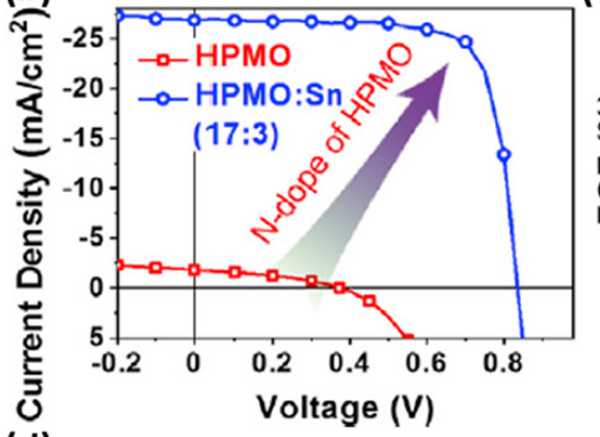

(d)

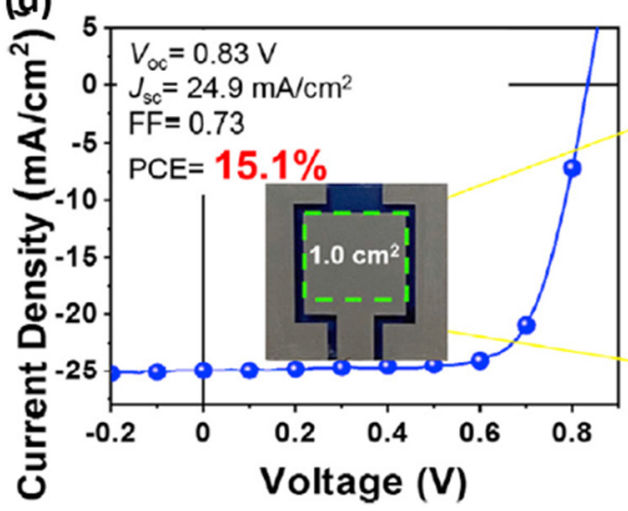

(c)
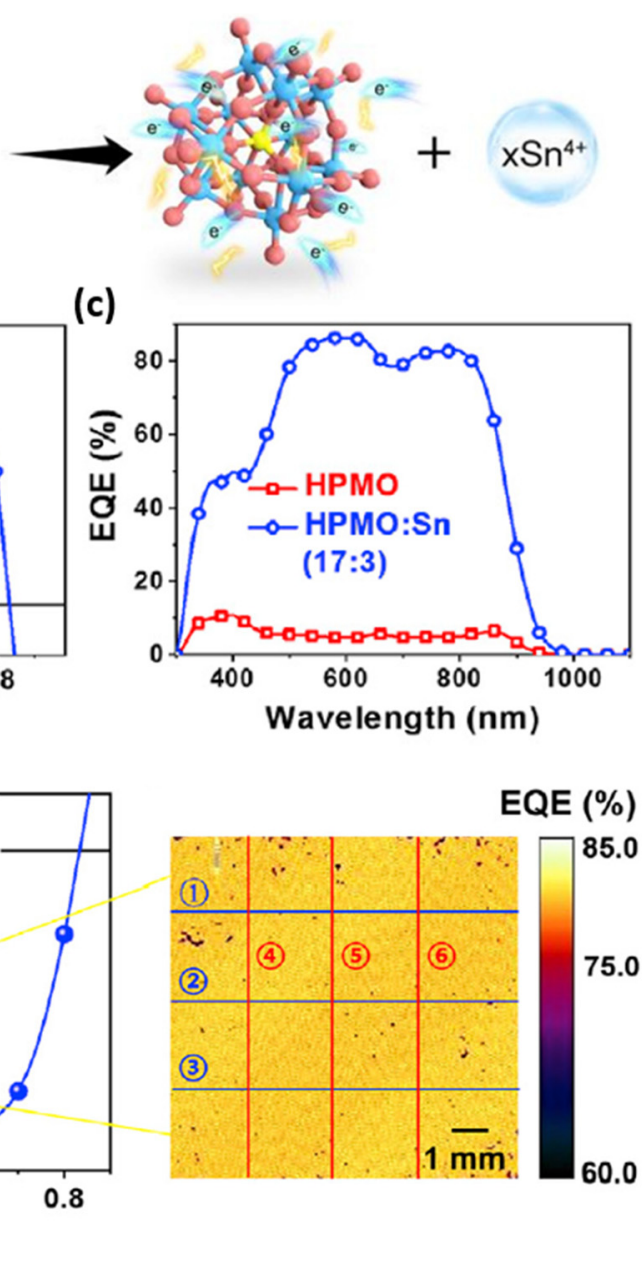

Figure 14. (a) Diagram of the reaction. (b) $J-V$ curves and (c) EQE spectra of corresponding OPVs. (d) $J-V$ curves and photovoltaic parameters of $1 \mathrm{~cm}^{2}$ OPVs. Mapping image of EQE at $500 \mathrm{~nm}$. Reproduced from [111]. Reprinted with permission from ref. [111]. Copyright 2021 Elsevier.

In the field of hybrid perovskite solar cells, self-assembled monolayers (SAMs) of organic small molecules have recently been developed to replace commonly used HTL materials, thereby enhancing PCE and improving stability of the cells. Surprisingly, the application of a SAM interlayer in OPVs has only attracted limited attention, so far. In 2021, Anthopoulos et al. reported that Br-2PACz modified ITO was used as a hole-extracting interlayer in OPVs based on PM6:BTP-eC9:PC 71 BM. The maximum PCE of OPVs reached 18.4\%, which was higher than the PCE value based on PEDOT:PSS (17.5\%) [112]. It is found that the relatively high PCE is due to the relatively high WF $(-5.81 \mathrm{eV})$ of ITO/Br-2PACz as compared to ITO/PEDOT:PSS $(4.9 \mathrm{eV})$, and the better active layer morphology with $\mathrm{Br}-$ 2PAC $z$ as HTL. The synergistic effects induced by Br-2PACz SAM result in cells with lower interface resistance, increased hole mobility and longer carrier lifetime. The important aspect is that the ITO/Br-2PACz electrode is chemically stable. The SAM removed can be recycled and reused to build OPVs with the same excellent performance. Therefore, Br-2PACz has the characteristics of process ability, low cost, adjustable electronic properties and chemical stability, which means that OPVs can be prepared with high efficiency and high stability.

\section{Summary and Perspectives}

Over 18\% PCE has been realized in single active layer and tandem structure OPVs in recent years, benefiting from the development of novel donor and acceptor materials, modification materials of the interface layer and device engineering. With the significant 
improvement of OPV equipment performance, the next step will be to make the technology more suitable for scale-up and commercialization. A list of possible future research directions follows: (1) At present, NFAs and wide bandgap donors have great development potential. Optimizing the structure of existing high-performance materials or developing novel materials with high charge mobility and low energy loss will play a vital role in constructing thick-film-based OPVs for meeting future commercial production. In-depth photophysical mechanism research of highly efficient OPV is also required, which can afford more valuable suggestions for material synthesis with higher performance. (2) Ternary OPV can achieve a wide absorption spectrum in a single active layer; tandem OPV can break through the Shockley-Queisser limit of single junction devices and achieve high $V_{\text {OC }}$. The combination of ternary strategy and tandem devices may be a promising method that can visibly increase PCE by more than 20\%. (3) A good interface modification layer is also crucial for the commercialization of OPV. The future development direction of interface modification layer materials might be excellent performance, simple preparation process, low cost and good compatibility with a large area printing process. (4) At the same time, exploring halogen-free and environment friendly green solvents and promoting the use of non-toxic solvent printing technology would all be conducive to environmental protection.

Author Contributions: Conceptualization, Q.S., J.G. and C.X.; writing-original draft preparation, X.W. and X.M.; writing-review and editing, X.M., J.W. and F.Z.; supervision, F.Z. All authors have read and agreed to the published version of the manuscript.

Funding: This research received no external funding.

Acknowledgments: This work was supported by the National Natural Science Foundation of China (61975006, 62075155), Postdoctoral Innovative Talent Support Program (BX20200042), China Postdoctoral Science Foundation (2020M680327), Beijing Natural Science Foundation (4192049).

Conflicts of Interest: The authors declare no conflict of interest.

\section{References}

1. Zhang, Y.; Wang, J.; Wang, X. Review on probabilistic forecasting of wind power generation. Renew. Sustain. Energy Rev. 2014, 32, 255-270. [CrossRef]

2. Lewis, N.S. Toward Cost-Effective Solar Energy Use. Science 2007, 315, 798-801. [CrossRef] [PubMed]

3. De Arquer, F.P.G.; Armin, A.; Meredith, P.; Sargent, E.H. Solution-processed semiconductors for next-generation photodetectors. Nat. Rev. Mater. 2017, 2, 16100. [CrossRef]

4. Gao, W.; An, Q.; Hao, M.; Sun, R.; Yuan, J.; Zhang, F.; Ma, W.; Min, J.; Yang, C. Thick-Film Organic Solar Cells Achieving over 11\% Efficiency and Nearly 70\% Fill Factor at Thickness over $400 \mathrm{~nm}$. Adv. Funct. Mater. 2020, 30, 1908336. [CrossRef]

5. An, Q.; Wang, J.; Zhang, F. Ternary polymer solar cells with alloyed donor achieving $14.13 \%$ efficiency and $78.4 \%$ fill factor. Nano Energy 2019, 60, 768-774. [CrossRef]

6. Wu, J.-S.; Cheng, S.-W.; Cheng, Y.-J.; Hsu, C.-S. Donor-acceptor conjugated polymers based on multifused ladder-type arenes for organic solar cells. Chem. Soc. Rev. 2015, 44, 1113-1154. [CrossRef]

7. $\mathrm{Hu}, \mathrm{Z} . ;$ Wang, Z.; An, Q.; Zhang, F. Semitransparent polymer solar cells with $12.37 \%$ efficiency and $18.6 \%$ average visible transmittance. Sci. Bull. 2020, 65, 131-137. [CrossRef]

8. Kwon, O.K.; Uddin, M.A.; Park, J.-H.; Park, S.K.; Nguyen, T.L.; Woo, H.Y.; Park, S.Y. A High Efficiency Nonfullerene Organic Solar Cell with Optimized Crystalline Organizations. Adv. Mater. 2016, 28, 910-916. [CrossRef]

9. Ma, X.; Zhang, F.; An, Q.; Sun, Q.; Zhang, M.; Zhang, J. Dramatically Boosted Efficiency of Small Molecule Solar Cells by Synergistically Optimizing Molecular Aggregation and Crystallinity. ACS Sustain. Chem. Eng. 2017, 5, 1982-1989. [CrossRef]

10. Zomerman, D.; Kong, J.; McAfee, S.M.; Welch, G.C.; Kelly, T.L. Control and Characterization of Organic Solar Cell Morphology Through Variable-Pressure Solvent Vapor Annealing. ACS Appl. Energy Mater. 2018, 1, 5663-5674. [CrossRef]

11. An, Q.; Ma, X.; Gao, J.; Zhang, F. Solvent additive-free ternary polymer solar cells with $16.27 \%$ efficiency. Sci. Bull. 2019, 64, 504-506. [CrossRef]

12. Schilinsky, P.; Waldauf, C.; Brabec, C.J. Recombination and loss analysis in polythiophene based bulk heterojunction photodetectors. Appl. Phys. Lett. 2002, 81, 3885-3887. [CrossRef]

13. Gao, J.; Wang, J.; Xu, C.; Hu, Z.; Ma, X.; Zhang, X.; Niu, L.; Zhang, J.; Zhang, F. A Critical Review on Efficient Thick-Film Organic Solar Cells. Sol. RRL 2020, 4, 2000364. [CrossRef]

14. Zeng, A.; Ma, X.; Pan, M.; Chen, Y.; Ma, R.; Zhao, H.; Zhang, J.; Kim, H.K.; Shang, A.; Luo, S.; et al. A Chlorinated Donor Polymer Achieving High-Performance Organic Solar Cells with a Wide Range of Polymer Molecular Weight. Adv. Funct. Mater. 2021, 31, 2102413. [CrossRef] 
15. Hu, Z.; Wang, J.; Wang, Z.; Gao, W.; An, Q.; Zhang, M.; Ma, X.; Wang, J.; Miao, J.; Yang, C.; et al. Semitransparent ternary nonfullerene polymer solar cells exhibiting $9.40 \%$ efficiency and $24.6 \%$ average visible transmittance. Nano Energy 2019,55 , 424-432. [CrossRef]

16. Lin, Y.; Wang, J.; Zhang, Z.-G.; Bai, H.; Li, Y.; Zhu, D.; Zhan, X. An Electron Acceptor Challenging Fullerenes for Efficient Polymer Solar Cells. Adv. Mater. 2015, 27, 1170-1174. [CrossRef]

17. Zhao, W.; Qian, D.; Zhang, S.; Li, S.; Inganäs, O.; Gao, F.; Hou, J. Fullerene-Free Polymer Solar Cells with over $11 \%$ Efficiency and Excellent Thermal Stability. Adv. Mater. 2016, 28, 4734-4739. [CrossRef] [PubMed]

18. Zhao, Z.; Xu, C.; Niu, L.; Zhang, X.; Zhang, F. Recent Progress on Broadband Organic Photodetectors and their Applications. Laser Photon. Rev. 2020, 14, 2000262. [CrossRef]

19. Yuan, J.; Zhang, Y.; Zhou, L.; Zhang, G.; Yip, H.-L.; Lau, T.-K.; Lu, X.; Zhu, C.; Peng, H.; Johnson, P.A.; et al. Single-Junction Organic Solar Cell with over 15\% Efficiency Using Fused-Ring Acceptor with Electron-Deficient Core. Joule 2019, 3, 1140-1151. [CrossRef]

20. Luo, Z.; Ma, R.; Liu, T.; Yu, J.; Xiao, Y.; Sun, R.; Xie, G.; Yuan, J.; Chen, Y.; Chen, K.; et al. Fine-Tuning Energy Levels via Asymmetric End Groups Enables Polymer Solar Cells with Efficiencies over 17\%. Joule 2020, 4, 1236-1247. [CrossRef]

21. Cui, Y.; Yao, H.; Zhang, J.; Xian, K.; Zhang, T.; Hong, L.; Wang, Y.; Xu, Y.; Ma, K.; An, C.; et al. Single-Junction Organic Photovoltaic Cells with Approaching 18\% Efficiency. Adv. Mater. 2020, 32, 1908205. [CrossRef] [PubMed]

22. Ma, Y.; Zhang, M.; Wan, S.; Yin, P.; Wang, P.; Cai, D.; Liu, F.; Zheng, Q. Efficient Organic Solar Cells from Molecular Orientation Control of M-Series Acceptors. Joule 2021, 5, 197-209. [CrossRef]

23. Cui, Y.; Yao, H.; Hong, L.; Zhang, T.; Tang, Y.; Lin, B.; Xian, K.; Gao, B.; An, C.; Bi, P.; et al. 17\% efficiency organic photovoltaic cell with superior processability. Natl. Sci. Rev. 2019, 7, 1239-1246. [CrossRef]

24. Ma, R.; Liu, T.; Luo, Z.; Guo, Q.; Xiao, Y.; Chen, Y.; Li, X.; Luo, S.; Lu, X.; Zhang, M.; et al. Improving open-circuit voltage by a chlorinated polymer donor endows binary organic solar cells efficiencies over 17\%. Sci. China Chem. 2020, 63, 325-330. [CrossRef]

25. Yao, J.; Qiu, B.; Zhang, Z.-G.; Xue, L.; Wang, R.; Zhang, C.; Chen, S.; Zhou, Q.; Sun, C.; Yang, C.; et al. Cathode engineering with perylene-diimide interlayer enabling over $17 \%$ efficiency single-junction organic solar cells. Nat. Commun. 2020, 11, 2726. [CrossRef]

26. Wang, T.; Sun, R.; Shi, M.; Pan, F.; Hu, Z.; Huang, F.; Li, Y.; Min, J. Solution-Processed Polymer Solar Cells with over 17\% Efficiency Enabled by an Iridium Complexation Approach. Adv. Energy Mater. 2020, 10, 2000590. [CrossRef]

27. Wu, J.; Li, G.; Fang, J.; Guo, X.; Zhu, L.; Guo, B.; Wang, Y.; Zhang, G.; Arunagiri, L.; Liu, F.; et al. Random terpolymer based on thiophene-thiazolothiazole unit enabling efficient non-fullerene organic solar cells. Nat. Commun. 2020, 11, 4612. [CrossRef]

28. Zhu, C.; Meng, L.; Zhang, J.; Qin, S.; Lai, W.; Qiu, B.; Yuan, J.; Wan, Y.; Huang, W.; Li, Y. A Quinoxaline-Based D-A Copolymer Donor Achieving 17.62\% Efficiency of Organic Solar Cells. Adv. Mater. 2021, 33, 2100474. [CrossRef] [PubMed]

29. Zhang, Z.; Li, Y.; Cai, G.; Zhang, Y.; Lu, X.; Lin, Y. Selenium Heterocyclic Electron Acceptor with Small Urbach Energy for As-Cast High-Performance Organic Solar Cells. J. Am. Chem. Soc. 2020, 142, 18741-18745. [CrossRef]

30. Liu, Q.; Jiang, Y.; Jin, K.; Qin, J.; Xu, J.; Li, W.; Xiong, J.; Liu, J.; Xiao, Z.; Sun, K.; et al. 18\% Efficiency organic solar cells. Sci. Bull. 2020, 65, 272-275. [CrossRef]

31. Li, C.; Zhou, J.; Song, J.; Xu, J.; Zhang, H.; Zhang, X.; Guo, J.; Zhu, L.; Wei, D.; Han, G.; et al. Non-fullerene acceptors with branched side chains and improved molecular packing to exceed 18\% efficiency in organic solar cells. Nat. Energy 2021, 6, 605-613. [CrossRef]

32. Jin, K.; Xiao, Z.; Ding, L. D18, an eximious solar polymer! J. Semicond. 2021, 42. [CrossRef]

33. Lin, Y.; Adilbekova, B.; Firdaus, Y.; Yengel, E.; Faber, H.; Sajjad, M.; Zheng, X.; Yarali, E.; Seitkhan, A.; Bakr, O.M.; et al. 17\% Efficient Organic Solar Cells Based on Liquid Exfoliated WS 2 as a Replacement for PEDOT:PSS. Adv. Mater. 2019, $31,1902965$. [CrossRef] [PubMed]

34. Li, D.; Zhu, L.; Liu, X.; Xiao, W.; Yang, J.; Ma, R.; Ding, L.; Liu, F.; Duan, C.; Fahlman, M.; et al. Enhanced and Balanced Charge Transport Boosting Ternary Solar Cells Over 17\% Efficiency. Adv. Mater. 2020, 32, 2002344. [CrossRef] [PubMed]

35. Lin, Y.; Firdaus, Y.; Nugraha, M.I.; Liu, F.; Karuthedath, S.; Emwas, A.; Zhang, W.; Seitkhan, A.; Neophytou, M.; Faber, H.; et al. 17.1\% Efficient Single-Junction Organic Solar Cells Enabled by n-Type Doping of the Bulk-Heterojunction. Adv. Sci. 2020, 7, 1903419. [CrossRef]

36. Cui, M.; Li, D.; Du, X.; Li, N.; Rong, Q.; Li, N.; Shui, L.; Zhou, G.; Wang, X.; Brabec, C.J.; et al. A Cost-Effective, Aqueous-SolutionProcessed Cathode Interlayer Based on Organosilica Nanodots for Highly Efficient and Stable Organic Solar Cells. Adv. Mater. 2020, 32, 2002973. [CrossRef]

37. Sun, R.; Wang, W.; Yu, H.; Chen, Z.; Xia, X.; Shen, H.; Guo, J.; Shi, M.; Zheng, Y.; Wu, Y.; et al. Achieving over 17\% efficiency of ternary all-polymer solar cells with two well-compatible polymer acceptors. Joule 2021, 5, 1548-1565. [CrossRef]

38. An, Q.; Wang, J.; Gao, W.; Ma, X.; Hu, Z.; Gao, J.; Xu, C.; Hao, M.; Zhang, X.; Yang, C.; et al. Alloy-like ternary polymer solar cells with over 17.2\% efficiency. Sci. Bull. 2020, 65, 538-545. [CrossRef]

39. Ma, X.; Wang, J.; Gao, J.; Hu, Z.; Xu, C.; Zhang, X.L.; Zhang, F. Achieving 17.4\% Efficiency of Ternary Organic Photovoltaics with Two Well-Compatible Nonfullerene Acceptors for Minimizing Energy Loss. Adv. Energy Mater. 2020, 10, 2001404. [CrossRef]

40. Ma, R.; Liu, T.; Luo, Z.; Gao, K.; Chen, K.; Zhang, G.; Gao, W.; Xiao, Y.; Lau, T.-K.; Fan, Q.; et al. Adding a Third Component with Reduced Miscibility and Higher LUMO Level Enables Efficient Ternary Organic Solar Cells. ACS Energy Lett. 2020, 5, 2711-2720. [CrossRef] 
41. Li, S.; Zhan, L.; Jin, Y.; Zhou, G.; Lau, T.; Qin, R.; Shi, M.; Li, C.; Zhu, H.; Lu, X.; et al. Asymmetric Electron Acceptors for High-Efficiency and Low-Energy-Loss Organic Photovoltaics. Adv. Mater. 2020, 32, 2001160. [CrossRef]

42. Ma, Q.; Jia, Z.; Meng, L.; Zhang, J.; Zhang, H.; Huang, W.; Yuan, J.; Gao, F.; Wan, Y.; Zhang, Z.; et al. Promoting charge separation resulting in ternary organic solar cells efficiency over 17.5\%. Nano Energy 2020, 78, 105272. [CrossRef]

43. An, Q.; Wang, J.; Ma, X.; Gao, J.; Hu, Z.; Liu, B.; Sun, H.; Guo, X.; Zhang, X.L.; Zhang, F. Two compatible polymer donors contribute synergistically for ternary organic solar cells with $17.53 \%$ efficiency. Energy Environ. Sci. 2020, 13, 5039-5047. [CrossRef]

44. Wang, X.; Sun, Q.; Gao, J.; Ma, X.; Son, J.H.; Jeong, S.Y.; Hu, Z.; Niu, L.; Woo, H.Y.; Zhang, J.; et al. Ternary Organic Photovoltaic Cells Exhibiting 17.59\% Efficiency with Two Compatible Y6 Derivations as Acceptor. Sol. RRL 2021, 5, 2100007. [CrossRef]

45. Chen, Y.; Bai, F.; Peng, Z.; Zhu, L.; Zhang, J.; Zou, X.; Qin, Y.; Kim, H.K.; Yuan, J.; Ma, L.; et al. Asymmetric Alkoxy and Alkyl Substitution on Nonfullerene Acceptors Enabling High-Performance Organic Solar Cells. Adv. Energy Mater. 2020, 11, 2003141. [CrossRef]

46. Gao, J.; Ma, X.; Xu, C.; Wang, X.; Son, J.H.; Jeong, S.Y.; Zhang, Y.; Zhang, C.; Wang, K.; Niu, L.; et al. Over 17.7\% efficiency ternary-blend organic solar cells with low energy-loss and good thickness-tolerance. Chem. Eng. J. 2022, 428, 129276. [CrossRef]

47. Ma, X.; Zeng, A.; Gao, J.; Hu, Z.; Xu, C.; Son, J.H.; Jeong, S.Y.; Zhang, C.; Li, M.; Wang, K.; et al. Approaching 18\% efficiency of ternary organic photovoltaics with wide bandgap polymer donor and well compatible Y6: Y6-1O as acceptor. Natl. Sci. Rev. 2021, 8, nwaa305. [CrossRef]

48. Lin, Y.; Nugraha, M.I.; Firdaus, Y.; Scaccabarozzi, A.D.; Aniés, F.; Emwas, A.-H.; Yengel, E.; Zheng, X.; Liu, J.; Wahyudi, W.; et al. A Simple n-Dopant Derived from Diquat Boosts the Efficiency of Organic Solar Cells to 18.3\%. ACS Energy Lett. 2020, 5, 3663-3671. [CrossRef]

49. Ye, F.; Yang, W.; Luo, D.; Zhu, R.; Gong, Q. Applications of cesium in the perovskite solar cells. J. Semicond. 2017, 38, 011003. [CrossRef]

50. Li, K.; Wu, Y.; Li, X.; Fu, H.; Zhan, C. 17.1\%-Efficiency organic photovoltaic cell enabled with two higher-LUMO-level acceptor guests as the quaternary strategy. Sci. China Chem. 2020, 63, 490-496. [CrossRef]

51. Zhang, W.; Huang, J.; Xu, J.; Han, M.; Su, D.; Wu, N.; Zhang, C.; Xu, A.; Zhan, C. Phthalimide Polymer Donor Guests Enable over 17\% Efficient Organic Solar Cells via Parallel-Like Ternary and Quaternary Strategies. Adv. Energy Mater. 2020, 10, 2001436. [CrossRef]

52. Li, X.; Zhou, L.; Lu, X.; Cao, L.; Du, X.; Lin, H.; Zheng, C.; Tao, S. Hydrogen bond induced high-performance quaternary organic solar cells with efficiency up to $17.48 \%$ and superior thermal stability. Mater. Chem. Front. 2021, 5, 3850-3858. [CrossRef]

53. Arunagiri, L.; Peng, Z.; Zou, X.; Yu, H.; Zhang, G.; Wang, Z.; Lai, J.Y.L.; Zhang, J.; Zheng, Y.; Cui, C.; et al. Selective Hole and Electron Transport in Efficient Quaternary Blend Organic Solar Cells. Joule 2020, 4, 1790-1805. [CrossRef]

54. Zhang, M.; Zhu, L.; Zhou, G.; Hao, T.; Qiu, C.; Zhao, Z.; Hu, Q.; Larson, B.W.; Zhu, H.; Ma, Z.; et al. Single-layered organic photovoltaics with double cascading charge transport pathways: 18\% efficiencies. Nat. Commun. 2021, 12, 309. [CrossRef]

55. Cui, Y.; Yao, H.; Zhang, J.; Zhang, T.; Wang, Y.; Hong, L.; Xian, K.; Xu, B.; Zhang, S.; Peng, J.; et al. Over 16\% efficiency organic photovoltaic cells enabled by a chlorinated acceptor with increased open-circuit voltages. Nat. Commun. 2019, 10, 2515. [CrossRef]

56. Hong, L.; Yao, H.; Wu, Z.; Cui, Y.; Zhang, T.; Xu, Y.; Yu, R.; Liao, Q.; Gao, B.; Xian, K.; et al. Eco-Compatible Solvent-Processed Organic Photovoltaic Cells with Over 16\% Efficiency. Adv. Mater. 2019, 31, 1903441. [CrossRef]

57. Chen, H.; Lai, H.; Chen, Z.; Zhu, Y.; Wang, H.; Han, L.; Zhang, Y.; He, F. 17.1 \%-Efficient Eco-Compatible Organic Solar Cells from a Dissymmetric 3D Network Acceptor. Angew. Chem. Int. Ed. 2021, 60, 3238-3246. [CrossRef] [PubMed]

58. Zhang, M.; Guo, X.; Ma, W.; Ade, H.; Hou, J. A Large-Bandgap Conjugated Polymer for Versatile Photovoltaic Applications with High Performance. Adv. Mater. 2015, 27, 4655-4660. [CrossRef]

59. Hu, Z.; Yang, L.; Gao, W.; Gao, J.; Xu, C.; Zhang, X.L.; Wang, Z.; Tang, W.; Yang, C.; Zhang, F. Over 15.7\% Efficiency of Ternary Organic Solar Cells by Employing Two Compatible Acceptors with Similar LUMO Levels. Small 2020, 16, 2000441. [CrossRef]

60. Zhang, S.; Qin, Y.; Zhu, J.; Hou, J. Over 14\% Efficiency in Polymer Solar Cells Enabled by a Chlorinated Polymer Donor. Adv. Mater. 2018, 30, 1800868. [CrossRef]

61. Fan, B.; Zhang, D.; Li, M.; Zhong, W.; Zeng, Z.; Ying, L.; Huang, F.; Cao, Y. Achieving over 16\% efficiency for single-junction organic solar cells. Sci. China Chem. 2019, 62, 746-752. [CrossRef]

62. Xiong, J.; Jin, K.; Jiang, Y.; Qin, J.; Wang, T.; Liu, J.; Liu, Q.; Peng, H.; Li, X.; Sun, A.; et al. Thiolactone copolymer donor gifts organic solar cells a 16.72\% efficiency. Sci. Bull. 2019, 64, 1573-1576. [CrossRef]

63. Xu, X.; Feng, K.; Bi, Z.; Ma, W.; Zhang, G.; Peng, Q. Single-Junction Polymer Solar Cells with 16.35\% Efficiency Enabled by a Platinum(II) Complexation Strategy. Adv. Mater. 2019, 31, 1901872. [CrossRef] [PubMed]

64. Zhang, M.; Xiao, Z.; Gao, W.; Liu, Q.; Jin, K.; Wang, W.; Mi, Y.; An, Q.; Ma, X.; Liu, X.; et al. Over 13\% Efficiency Ternary Nonfullerene Polymer Solar Cells with Tilted Up Absorption Edge by Incorporating a Medium Bandgap Acceptor. Adv. Energy Mater. 2018, 8, 1801968. [CrossRef]

65. Zhao, Z.; Li, C.; Shen, L.; Zhang, X.; Zhang, F. Photomultiplication type organic photodetectors based on electron tunneling injection. Nanoscale 2020, 12, 1091-1099. [CrossRef]

66. Du, X.; Yuan, Y.; Zhou, L.; Lin, H.; Zheng, C.; Luo, J.; Chen, Z.; Tao, S.; Liao, L. Delayed Fluorescence Emitter Enables Near 17\% Efficiency Ternary Organic Solar Cells with Enhanced Storage Stability and Reduced Recombination Energy Loss. Adv. Funct. Mater. 2020, 30, 1909837. [CrossRef] 
67. Ma, X.; Gao, W.; Yu, J.; An, Q.; Zhang, M.; Hu, Z.; Wang, J.; Tang, W.; Yang, C.; Zhang, F. Ternary nonfullerene polymer solar cells with efficiency $>13.7 \%$ by integrating the advantages of the materials and two binary cells. Energy Environ. Sci. 2018, 11, 2134-2141. [CrossRef]

68. Yan, T.; Ge, J.; Lei, T.; Zhang, W.; Song, W.; Fanady, B.; Zhang, D.; Chen, S.; Peng, R.; Ge, Z. 16.55\% efficiency ternary organic solar cells enabled by incorporating a small molecular donor. J. Mater. Chem. A 2019, 7, 25894-25899. [CrossRef]

69. An, Q.; Zhang, F.; Zhang, J.; Tang, W.; Deng, Z.; Hu, B. Versatile ternary organic solar cells: A critical review. Energy Environ. Sci. 2016, 9, 281-322. [CrossRef]

70. Chen, S.; Yan, T.; Fanady, B.; Song, W.; Ge, J.; Wei, Q.; Peng, R.; Chen, G.; Zou, Y.; Ge, Z. High efficiency ternary organic solar cells enabled by compatible dual-donor strategy with planar conjugated structures. Sci. China Chem. 2020, 63, 917-923. [CrossRef]

71. Wang, Y.; Wang, F.; Gao, J.; Yan, Y.; Wang, X.; Wang, X.; Xu, C.; Ma, X.; Zhang, J.; Zhang, F. Organic photovoltaics with 300 nm thick ternary active layer exhibiting $15.6 \%$ efficiency. J. Mater. Chem. C 2021, 9. [CrossRef]

72. Jiang, H.; Li, X.; Wang, J.; Qiao, S.; Zhang, Y.; Zheng, N.; Chen, W.; Li, Y.; Yang, R. Ternary Polymer Solar Cells with High Efficiency of $14.24 \%$ by Integrating Two Well-Complementary Nonfullerene Acceptors. Adv. Funct. Mater. 2019, $29,1903596$. [CrossRef]

73. Zhang, M.; Gao, W.; Zhang, F.; Mi, Y.; Wang, W.; An, Q.; Wang, J.; Ma, X.; Miao, J.; Hu, Z.; et al. Efficient ternary non-fullerene polymer solar cells with PCE of $11.92 \%$ and FF of 76.5\%. Energy Environ. Sci. 2018, 11, 841-849. [CrossRef]

74. Liu, M.; Wang, J.; Zhao, Z.; Yang, K.; Durand, P.; Ceugniet, F.; Ulrich, G.; Niu, L.; Ma, Y.; Leclerc, N.; et al. Ultra-Narrow-Band NIR Photomultiplication Organic Photodetectors Based on Charge Injection Narrowing. J. Phys. Chem. Lett. 2021, 12, 2937-2943. [CrossRef] [PubMed]

75. Cheng, P.; Liu, Y.; Chang, S.-Y.; Li, T.; Sun, P.; Wang, R.; Cheng, H.-W.; Huang, T.; Meng, L.; Nuryyeva, S.; et al. Efficient Tandem Organic Photovoltaics with Tunable Rear Sub-cells. Joule 2019, 3, 432-442. [CrossRef]

76. Ma, X.; An, Q.; Ibraikulov, O.; Lévêque, P.; Heiser, T.; Leclerc, N.; Zhang, X.; Zhang, F. Efficient ternary organic photovoltaics with two polymer donors by minimizing energy loss. J. Mater. Chem. A 2020, 8, 1265-1272. [CrossRef]

77. Jiang, K.; Wei, Q.; Lai, J.Y.L.; Peng, Z.; Kim, H.K.; Yuan, J.; Ye, L.; Ade, H.; Zou, Y.; Yan, H. Alkyl Chain Tuning of Small Molecule Acceptors for Efficient Organic Solar Cells. Joule 2019, 3, 3020-3033. [CrossRef]

78. Ma, X.; Luo, M.; Gao, W.; Yuan, J.; An, Q.; Zhang, M.; Hu, Z.; Gao, J.; Wang, J.; Zou, Y.; et al. Achieving 14.11\% efficiency of ternary polymer solar cells by simultaneously optimizing photon harvesting and exciton distribution. J. Mater. Chem. A 2019, 7, 7843-7851. [CrossRef]

79. Zhao, Z.; Wang, J.; Xu, C.; Yang, K.; Zhao, F.; Wang, K.; Zhang, X.L.; Zhang, F. Photomultiplication Type Broad Response Organic Photodetectors with One Absorber Layer and One Multiplication Layer. J. Phys. Chem. Lett. 2020, 11, 366-373. [CrossRef]

80. Yan, C.; Tang, H.; Ma, R.; Zhang, M.; Liu, T.; Lv, J.; Huang, J.; Yang, Y.; Xu, T.; Kan, Z.; et al. Synergy of Liquid-Crystalline Small-Molecule and Polymeric Donors Delivers Uncommon Morphology Evolution and 16.6\% Efficiency Organic Photovoltaics. Adv. Sci. 2020, 7, 2000149. [CrossRef]

81. Xu, C.; Chen, H.; Zhao, Z.; Gao, J.; Ma, X.; Lu, S.; Zhang, X.; Xiao, Z.; Zhang, F. 14.46\% Efficiency small molecule organic photovoltaics enabled by the well trade-off between phase separation and photon harvesting. J. Energy Chem. 2021, 57, 610-617. [CrossRef]

82. Song, J.; Li, C.; Zhu, L.; Guo, J.; Xu, J.; Zhang, X.; Weng, K.; Zhang, K.; Min, J.; Hao, X.; et al. Ternary Organic Solar Cells with Efficiency $>16.5 \%$ Based on Two Compatible Nonfullerene Acceptors. Adv. Mater. 2019, 31, 1905645. [CrossRef] [PubMed]

83. Zhao, Z.; Liu, B.; Xu, C.; Liu, M.; Yang, K.; Zhang, X.L.; Xu, Y.; Zhang, J.; Li, W.; Zhang, F. Highly sensitive all-polymer photodetectors with ultraviolet-visible to near-infrared photo-detection and their application as an optical switch. J. Mater. Chem. C 2021, 9, 5349-5355. [CrossRef]

84. Lu, L.; Kelly, M.A.; You, W.; Yu, L. Status and prospects for ternary organic photovoltaics. Nat. Photon. 2015, 9, 491-500. [CrossRef]

85. An, Q.; Zhang, F.; Gao, W.; Sun, Q.; Zhang, M.; Yang, C.; Zhang, J. High-efficiency and air stable fullerene-free ternary organic solar cells. Nano Energy 2018, 45, 177-183. [CrossRef]

86. Mohapatra, A.A.; Kim, V.; Puttaraju, B.; Sadhanala, A.; Jiao, X.; McNeill, C.R.; Friend, R.H.; Patil, S. Förster Resonance Energy Transfer Drives Higher Efficiency in Ternary Blend Organic Solar Cells. ACS Appl. Energy Mater. 2018, 1, 4874-4882. [CrossRef]

87. Yang, K.; Wang, J.; Zhao, Z.; Zhou, Z.; Liu, M.; Zhang, J.; He, Z.; Zhang, F. Smart Strategy: Transparent Hole-Transporting Polymer as a Regulator to Optimize Photomultiplication-type Polymer Photodetectors. ACS Appl. Mater. Interfaces 2021, 13, 21565-21572. [CrossRef]

88. Yang, L.; Yan, L.; You, W. Organic Solar Cells beyond One Pair of Donor-Acceptor: Ternary Blends and More. J. Phys. Chem. Lett. 2013, 4, 1802-1810. [CrossRef] [PubMed]

89. Zhan, L.; Li, S.; Lau, T.-K.; Cui, Y.; Lu, X.; Shi, M.; Li, C.-Z.; Li, H.; Hou, J.; Chen, H. Over 17\% efficiency ternary organic solar cells enabled by two non-fullerene acceptors working in an alloy-like model. Energy Environ. Sci. 2020, 13, 635-645. [CrossRef]

90. Fu, H.; Wang, Z.; Sun, Y. Advances in Non-Fullerene Acceptor Based Ternary Organic Solar Cells. Sol. RRL 2018, 2, 1700158. [CrossRef]

91. Yang, K.; Wang, J.; Zhao, Z.; Zhao, F.; Wang, K.; Zhang, X.; Zhang, F. Ultraviolet to near-infrared broadband organic photodetectors with photomultiplication. Org. Electron. 2020, 83, 105739. [CrossRef]

92. Hu, Z.; Wang, J.; Ma, X.; Gao, J.; Xu, C.; Wang, X.; Zhang, X.; Wang, Z.; Zhang, F. Semitransparent organic solar cells exhibiting $13.02 \%$ efficiency and $20.2 \%$ average visible transmittance. J. Mater. Chem. A 2021, 9, 6797-6804. [CrossRef] 
93. Li, D.; Chen, X.; Cai, J.; Li, W.; Chen, M.; Mao, Y.; Du, B.; Smith, J.; Kilbride, R.C.; O’Kane, M.E.; et al. Non-fullerene acceptor fibrils enable efficient ternary organic solar cells with $16.6 \%$ efficiency. Sci. China Chem. 2020, 63, 1461-1468. [CrossRef]

94. Gao, J.; Wang, J.; An, Q.; Ma, X.; Hu, Z.; Xu, C.; Zhang, X.; Zhang, F. Over 16.7\% efficiency of ternary organic photovoltaics by employing extra PC71BM as morphology regulator. Sci. China Chem. 2019, 63, 83-91. [CrossRef]

95. Jiang, M.; Bai, H.; Zhi, H.; Yan, L.; Woo, H.Y.; Tong, L.; Wang, J.; Zhang, F.; An, Q. Rational compatibility in a ternary matrix enables all-small-molecule organic solar cells with over 16\% efficiency. Energy Environ. Sci. 2021, 14, 3945-3953. [CrossRef]

96. Yan, T.; Song, W.; Huang, J.; Peng, R.; Huang, L.; Ge, Z. 16.67\% Rigid and 14.06\% Flexible Organic Solar Cells Enabled by Ternary Heterojunction Strategy. Adv. Mater. 2019, 31, 1902210. [CrossRef]

97. Luo, Z.; Sun, R.; Zhong, C.; Liu, T.; Zhang, G.; Zou, Y.; Jiao, X.; Min, J.; Yang, C. Altering alkyl-chains branching positions for boosting the performance of small-molecule acceptors for highly efficient nonfullerene organic solar cells. Sci. China Chem. 2020, 63, 361-369. [CrossRef]

98. Chang, Y.; Lau, T.-K.; Pan, M.-A.; Lu, X.; Yan, H.; Zhan, C. The synergy of host-guest nonfullerene acceptors enables $16 \%$-efficiency polymer solar cells with increased open-circuit voltage and fill-factor. Mater. Horizons 2019, 6, 2094-2102. [CrossRef]

99. Menke, S.M.; Ran, N.A.; Bazan, G.C.; Friend, R.H. Understanding Energy Loss in Organic Solar Cells: Toward a New Efficiency Regime. Joule 2018, 2, 25-35. [CrossRef]

100. Yu, R.; Yao, H.; Cui, Y.; Hong, L.; He, C.; Hou, J. Improved Charge Transport and Reduced Nonradiative Energy Loss Enable Over 16\% Efficiency in Ternary Polymer Solar Cells. Adv. Mater. 2019, 31, 1902302. [CrossRef]

101. Ma, X.; Wang, J.; An, Q.; Gao, J.; Hu, Z.; Xu, C.; Zhang, X.; Liu, Z.; Zhang, F. Highly efficient quaternary organic photovoltaics by optimizing photogenerated exciton distribution and active layer morphology. Nano Energy 2020, 70, 20104496. [CrossRef]

102. Guillemoles, J.-F.; Kirchartz, T.; Cahen, D.; Rau, U. Guide for the perplexed to the Shockley-Queisser model for solar cells. Nat. Photon. 2019, 13, 501-505. [CrossRef]

103. Liu, M.; Wang, J.; Yang, K.; Zhao, Z.; Zhou, Z.; Ma, Y.; Shen, L.; Ma, X.; Zhang, F. Highly sensitive, broad-band organic photomultiplication-type photodetectors covering UV-Vis-NIR. J. Mater. Chem. C 2021, 9, 6357-6364. [CrossRef]

104. Meng, L.; Zhang, Y.; Wan, X.; Li, C.; Zhang, X.; Wang, Y.; Ke, X.; Xiao, Z.; Ding, L.; Xia, R. Organic and solution-processed tandem solar cells with 17.3\% efficiency. Science 2018, 361, 1094-1098. [CrossRef] [PubMed]

105. Hu, Z.; Wang, J.; Ma, X.; Gao, J.; Xu, C.; Yang, K.; Wang, Z.; Zhang, J.; Zhang, F. A critical review on semitransparent organic solar cells. Nano Energy 2020, 78, 20105376. [CrossRef]

106. Ho, C.H.Y.; Kim, T.; Xiong, Y.; Firdaus, Y.; Yi, X.; Dong, Q.; Rech, J.J.; Gadisa, A.; Booth, R.; O'Connor, B.T.; et al. High-Performance Tandem Organic Solar Cells Using HSolar as the Interconnecting Layer. Adv. Energy Mater. 2020, 10, 2000823. [CrossRef]

107. Liu, G.; Xia, R.; Huang, Q.; Zhang, K.; Hu, Z.; Jia, T.; Liu, X.; Yip, H.; Huang, F. Tandem Organic Solar Cells with $18.7 \%$ Efficiency Enabled by Suppressing the Charge Recombination in Front Sub-Cell. Adv. Funct. Mater. 2021, 31, 2103283. [CrossRef]

108. Chen, W.; Sun, H.; Hu, Q.; Djurišić, A.B.; Russell, T.P.; Guo, X.; He, Z. High Short-Circuit Current Density via Integrating the Perovskite and Ternary Organic Bulk Heterojunction. ACS Energy Lett. 2019, 4, 2535-2536. [CrossRef]

109. Zhao, Z.; Liu, B.; Xie, C.; Ma, Y.; Wang, J.; Liu, M.; Yang, K.; Xu, Y.; Zhang, J.; Li, W. Highly sensitive, sub-microsecond polymer photodetectors for blood oxygen saturation testing. Sci. China Chem. 2021, 64. [CrossRef]

110. Zeng, M.; Wang, X.; Ma, R.; Zhu, W.; Li, Y.; Chen, Z.; Zhou, J.; Li, W.; Liu, T.; He, Z.; et al. Dopamine Semiquinone Radical Doped PEDOT:PSS: Enhanced Conductivity, Work Function and Performance in Organic Solar Cells. Adv. Energy Mater. 2020, 10, 2000743. [CrossRef]

111. Kang, Q.; Zheng, Z.; Zu, Y.; Liao, Q.; Bi, P.; Zhang, S.; Yang, Y.; Xu, B.; Hou, J. n-doped inorganic molecular clusters as a new type of hole transport material for efficient organic solar cells. Joule 2021, 5, 646-658. [CrossRef]

112. Lin, Y.; Magomedov, A.; Firdaus, Y.; Kaltsas, D.; El-Labban, A.; Faber, H.; Naphade, D.R.; Yengel, E.; Zheng, X.; Yarali, E.; et al. 18.4\% Organic Solar Cells Using a High Ionization Energy Self-Assembled Monolayer as Hole-Extraction Interlayer. ChemSusChem 2021, 2100707. [CrossRef] [PubMed] 